$\mathrm{DOE} / \mathrm{MC} / 11076--3049$

DE92 001130

\title{
Preparation For Upgrading Western Subbituminous Coal
}

\section{Topical Report}

\author{
R.W. Grimes \\ C.Y. Cha \\ D.C. Sheesley
}

November 1990

Work Performed Under Cooperative Agreement: DE-FC21-86MC11076

For

U.S. Department of Energy

Office of Fossil Energy

Morgantown Energy Technology Center

Morgantown, West Virginia

By

Western Research Institute

Laramie, Wyoming 


\section{DISCLAIMER}

This report was prepared as an account of work sponsored by an agency of the United States Government. Neither the United States Government nor any agency thereof, nor any of their employees makes any warranty, express or implied, or assumes any legal liability or responsibility for the accuracy, completeness or usefulness of any information, apparatus, product, or process disclosed, or represents that its use would not infringe privately owned rights. Reference herein to any specific commercial product, process, or service by trade name, trademark, manufacturer, or otherwise, does not necessarily constitute or imply its endorsement, recommendation, or favoring by the United States Government or any agency thereof. The views and opinions of authors expressed herein do not necessarily state or reflect those of the United States Government or any agency thereof.

This report has been reproduced directly from the best available copy.

Available to DOE and DOE contractors from the Office of Scientific and Technical Information, P.O. Box 62, Oak Ridge, TN 37831; prices available from (615)576-8401, FTS 626-8401.

Available to the public from the National Technical Information Service, U.S. Department of Commerce, 5285 Port Royal Rd., Springfield, VA 22161. 


\title{
Preparation For Upgrading Western Subbituminous Coal
}

\section{Topical Report}

\author{
R.W. Grimes \\ C.Y. Cha \\ D.C. Sheesley .
}

Work Performed Under Cooperative Agreement: DE-FC21-86MC11076

\author{
For \\ U.S. Department of Energy \\ Office of Fossil Energy \\ Morgantown Energy Technology Center \\ P.O. Box 880 \\ Morgantown, West Virginia 26507-0880
Western Research Institute
P.O. Box 3395
University Station
Laramie, Wyoming 82071 \\ By
}

November 1990 
IIST OF TABLES AND FIGURES $\ldots \ldots \ldots \ldots \ldots \ldots \ldots \ldots \ldots \ldots \ldots \ldots \ldots \ldots \ldots$

ABSTRACT ................................... vi

EXECUTIVE SUMMARY $\ldots \ldots \ldots \ldots \ldots \ldots \ldots \ldots \ldots \ldots \ldots \ldots \ldots \ldots \ldots$

INTRODUCTION ......................................

WESTERN COAL CHARACTERISTICS........................... 1

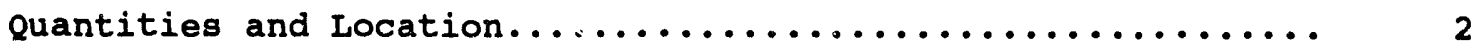

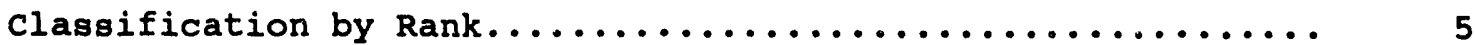

Proximate and Ultimate Analyses...................... 9

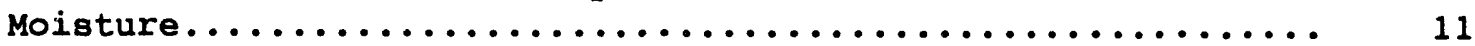

Ash Characteristics............................. 12

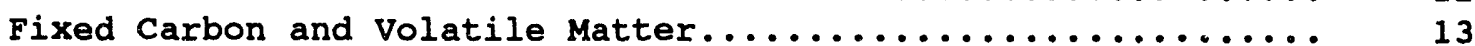

sulfur..................................... 14

Heating value................................... 14

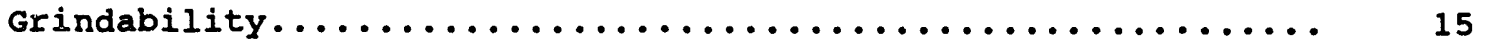

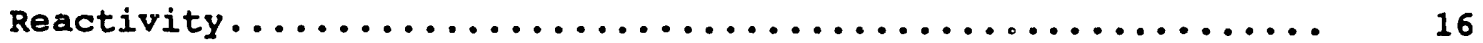

Agglomeration and weathering....................... 18

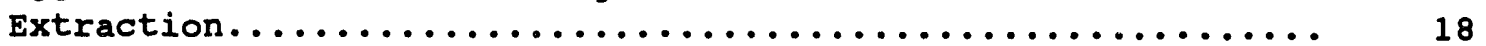

summary of Western Coal Characteristics.................. 19

THE U.S. COAL MARKET................................... 19

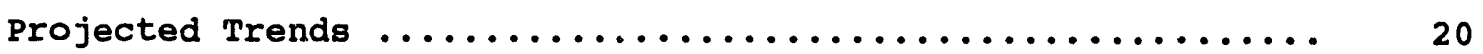

Western subbituminous Coal Markets ..................... 22

Coal specifications for Electric Utilities................ 26

criteria for Upgrading Western subbituminous coal......... 27

COAL PREPARATION..................................... 29

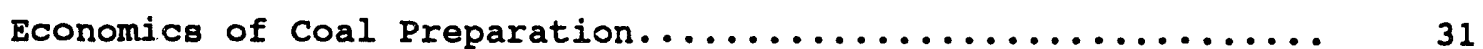

Essential Coal Preparation......................... 32

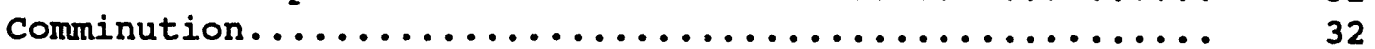

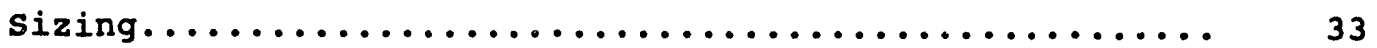

storage and Handling.......................... 34

Disposal of Refuse from Coal Beneficiation........... 35

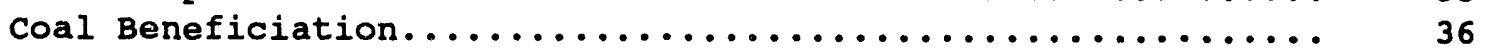

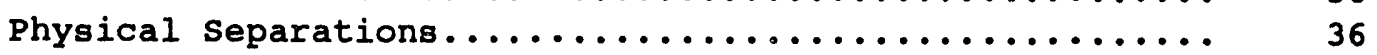

Gravity separations......................... 37

Separations Using surface Properties................ 38

Magnetic separations........................... 40 


\section{Page}

Chemical coal cleaning......................... 41

Moisture Reduction............................ 43

Mechanical Dewatering....................... 44

Thermal Drying........................... 45

Existing Thermal Drying Processes................ 48

Developmental Drying Technologies.............. 52

Briquetting and Pelletizing.................... 56

BEST TECHNOLOGIES TO UPGRADE WESTERN COAL................. 57

RECOMMENDED AREAS FOR FURTHER RESEARCH.................... 59

ACKNOWLEDGMENT .....................................

DISCLAIMER. ....................................

REFERENCES CITED..................................

ADDITIONAL SOURCES OF INFORMATION ...................... 66 
1. AstM classification by Rank..................... 6

2. Proximate and Ultimate Analyses of selected Coals....... 10

3. Mineral Analysis of Ash of Selected Coals............. 12

4. 1982 Coal Specifications of Some Eastern Utilities....... 27

5. R.O.M. and Thermal-Dried Powder River Basin Coal with Coal specifications for an Eastern Utility......... 58

\section{Figure}

1. Western Portion of U.S. Demonstrated Reserve Base for Coal

2. Distribution of Western Coal Demonstrated Reserve Base by state.................................

3. Western Coal by Rank........................... 8

4. Variability of the Hardgrove Grindability Index with Volatile Matter Content (Rank).................... 17

5. Marketg for wyoming coal......................... 24

6. Distribution of wyoming Coal..................... 25

7. Typical Drying Curve............................ 47 
The objective of this project was to establish the physical and chemical characteristics of western coal and determine the best preparation technologies for upgrading this resource. Western coal was characterized as an abundant, easily mineable, clean, low-sulfur coal with low heating value, high moisture, susceptibility to spontaneous ignition, and considerable transit distances from major markets.

Project support was provided by the Morgantown Energy Technology Center (METC) of the U.S. Department of Energy (DOE). The research was conducted by the Western Research Institute, (WRI) in Laramie, Wyoming. The project scope of work required the completion of four tasks: (1) project planning, (2) literature searches and verbal contacts with consumers and producers of western coal, (3) selection of the best technologies to upgrade western coal, and (4) identification of research needed to develop the best technologies for upgrading western coals.

The results of this research suggest that thermal drying is the best technology for upgrading western coals. There is a significant need for further research in areas involving physical and chemical stabilization of the dried coal product. Excessive particle-size degradation and resulting dustiness, moisture reabsorption, and high susceptibility to spontaneous combustion are key areas requiring further research. Improved testing methods for the determination of equilibrium moisture and susceptibility to spontaneous ignition under various ambient conditions are recommended. 


\section{EXECUTIVE SUMARARY}

Sufficient quantities of clean western coal are available to meet the energy demands of the united states for many decades. However, the use of western coal is not without problems. The objective of this work is to identify advanced processes for beneficiation of western coals for the purpose of improving the market potential of these fuels. Project support was provided by the Morgantown Energy Technology Center (METC), and the work was done at the Western Research Institute (WRI) in Laramie, Wyoming.

Nearly one-half of the demonstrated reserve base of U.S. coal lies in the western coal-producing region. Nearly 80 of the total western demonstrated reserve lies in the states of Montana and Wyoming, much of which is located in the powder River Basin. The huge reserves of lowsulfur subbituminous coal in thick surface-mineable seams make the Powder River Basin extremely important in the U.S. energy picture.

Coal of all ranks is represented in the western region; however, low-rank coals dominate the western reserve. Subbituminous coals account for about 181 billion tons, or nearly 76.68 , of the western reserve base. Nearly all of the subbituminous coal in the United states is found in the western region. The western reserve also includes about 30.3 billion tons of lignite and 24.7 billion tons of bituminous coal. From the standpoint of reserve tonnage and production, western coal can clearly be characterized as low-rank, mainly subbituminous coal.

The typical western coal has a low heating value ranging from about 6,300 to $10,000 \mathrm{Btu} / 1 \mathrm{~b}$. A high moisture content of from 12 to 308 is largely responsible for the low heating value and accounts for many of the handling, storage, and combustion problems commonly associated with this resource. Ash quantities are low (generally less than 108) with softening temperatures of around $2200^{\circ} \mathrm{F}\left(1200^{\circ} \mathrm{C}\right)$. Western coal ash is a lignite-type ash, typically high in alkalis.

Western coal is low-sulfur coal, with sulfur content typically less than 18. In contrast to eastern and midwestern coals, much of the sulfur in western coal (around 668) is in the organic form. Western coals tend to weather or "slack" upon exposure to air, leading to problems with excessive dustiness and loss of product from storage piles. Typical western coals are more reactive to oxygen and tend to be more susceptible to spontaneous ignition chan eastern coals.

The majority of western coal production comes from surface mines. Thick seams and surface mining techniques produce a coal with little extraneous dilution and minimum extraction costs. Western coal is typically transported by unit train to markets in many states where it is primarily used as a steam coal for electric power generation. The :leanliness and low-sulfur content of western coal make it a desirable fuel for many utilities; however, low heating value, high moisture, and high transportation costs limit its market. Preparation techniques that reduce mineral matter and sulfur, particularly those that reduce only inorganic sulfur, are of little value to the typical western coal. 
Moisture reduction by thermal drying can decrease transportation costs, increase heating value, and improve many combustion characteristics of western coal, making it the most viable preparation technology for upgrading this resource.

Thermal drying of large tonnages of western coal presents some special problems. Western coal moisture is typically inherent moisture that requires high particle temperatures for removal. Typical thermal dryers, using heated air as the drying media, are highly susceptible to fires and explosions at high temperatures, and the dried coal they produce will reabsorb moisture to near its predried level upon exposure to high humidity.

Careful review of the available literature on western coal and coal preparation has led to the following recommendations for research and development:

- Of greatest significance to the upgrading of western coal is the development and demonstration of a drying technology that can dry large coal partisles to low moisture while maintaining particle size and integrity. Particle-size degradation and the resulting product dustiness are major problems with current drying technologies. The solution of these problems will represent a major advance in western coal technology.

- Stabilization of western coal, particularly stabilization of dried western coal, is an area requiring further research. Development of a product stabilization process that reduces 1088 to dusting and decreases liability to spontaneous combustion will greatly benefit the resource.

- The establishment of a procedure that can quantify the susceptibility of a given coal to spontaneous combustion under various ambient conditions will be of significant value in expanding the marketability of western coal.

- A method of determining equilibrium moisture that will accurately assess the moisture content one can axpect of a given coal under specific ambient conditions will be of great value to the western coal industry as the use of thermal drying increases.

- Development of methods to better use coal fines will benefit the coal industry. Research into the handing, storage, and transportation of coal fines can solve some important problems as more fine coal is generated by modern mining and preparation practices. 
Historically, the signifj.cance of coal as a fuel source cannot be overemphasized. It was coal that fired the boilers of the industrial revolution, heated the homes of the people, and provided the gas that illuminated their cities. Coal was the source of coke that fired the blast furnaces and reduced the iron ore, creating the iron and ateel from which the machinery of the day was constructed.

The byproducts of coking and gasification were the raw materials of a newly forming organic chemicals industry; the tars and pitches sealed the ships of transoceanic commerce. Coal was converted to liquid fuels, upon which much of the German army relied during World War II.

The end of the second world war saw a shift away from coal toward petroleum as the major source of the world's fuel and chemical feedstocks. It looked as though the abundant and economical supply of petroleum with its ease of handling and variety of refined products would soon replace coal as a fuel in all but the iron and steel industries. It was not until the $1970 \mathrm{~s}$ when the limited nature of the petroleum reserve became evident that we began to look once again to coal to fulfill our growing energy demands.

The currently known and accessible reserves of western coal are sufficient to meet our energy requirements well into the next century. The role that western coals will play in meeting future energy needs will be determined by many factors including environmental, economic and political conditions, and awareness.

Huge reserves of subbituminous coal lie close to the surface in western states. Thick seams and shallow overburden combine to make western coal America's least expensive energy at the source, but low heating value and high transportation costs tend to offset western coal's low mine-mouth price. The development of appropriate preparation technologies to upgrade western coals will help the U.S. efforts toward energy independence.

\section{WESTERH CONL CHARACTERISTICS}

Nearly one-half of the U.S. coal reserves lie in the western coalproducing region. Western coal can make a significant contribution toward energy independence for the United States; however, significant basic differences between this resource and its eastern counterpart limit its acceptability in some markets.

Typical western coals are noncaking coals of little value in standard metallurgical applications. The limited industrial base in the western United States restricts industrial use of these coals. Western coals have found acceptance in the electric utilities industry where their low sulfur content has helped many generators meet sulfur oxides emissions restrictions. 


\section{Quantities and Location}

Coal resources and reserves are defined in a manner similar to that used for other minerals. Resources generally refer to the quantity of coal in the ground in such concentrations that economic extraction is currently feasible or may be feasible in the near future. Reserves are a subset of resources than can be mined at the time of the estimate, based on current economic and technological feasibility, and that demonstrate a high degree of geologic certainty (EPRI 1980). Reserves generally exhibit a higher minimum seam thickness and lower maximum seam depth than do resources.

The Energy Information Administration, U.S. Department of Energy (DOE), divides the United states demonstrated reserve base for coal into three regions (Appalachian, interior, and western). For the purpose of this report, we will define western coal as coal occurring in the western region as designated by the DOE demonstrated reserve-base figures. The pie chart in Figure 1 illustrates the significance of the western portion of the U.S. coal resource reserve base.

DOE lists western coals as that portion of the national resource occurring in the states of Alaska, Arizona, Colorado, Idaho, Montana, New Mexico, North Dakota, oregon, South Dakota, Utah, Washington, and wyoming. In 1982, the demonstrated reserve base for these states totaled some 236,670 million tons; however, the actual resource will be many times this figure. The hypothetical resource for Alaska alone is estimated at greater than 5.6 trillion tons, which is more than the identified resource in 1972 for the entire United states (Keystone 1987 ).

Mineable deposits of coal are found in all of the western states; however, it should be noted that of the 236,700 million tons of western demonstrated reserve, 190,000 million tons (80.38 of the total) is located in just two states. Montana holds the greatest portion of the reserve with 120,300 million tons followed by wyoming with 69,700 million tons. Colorado, with 17,200 millions tons, is third with regard to demonstrated reserve in the western region. No other states in the western region have a demonstrated reserve in excess of ten thousand million tons. Figure 2 graphically depicts the distribution of western coal by state.

The Powder River Coal Basin in northeastern wyoming and southeastern Montana represents the largest known single body of energy in the world today and the lowest cost energy, on a Btu basis, at the source. The importance of this reserve with regard to the united states energy picture cannot be overemphasized. This reserve plays a very significant role in determining the characteristics of western coal. 


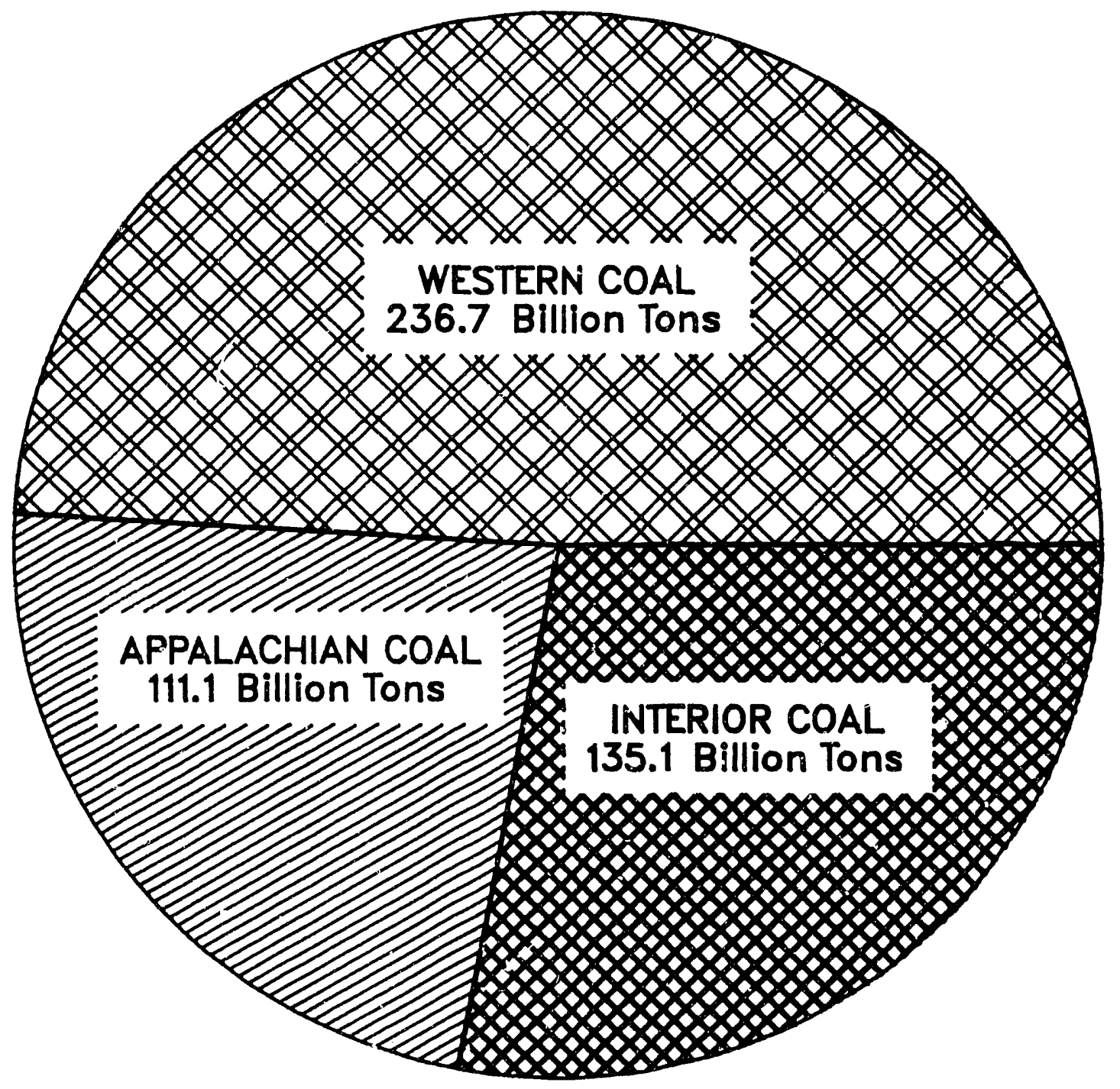

Figure 1. Western Portion of U.S. Demonstrated Reserve Base for Coal 


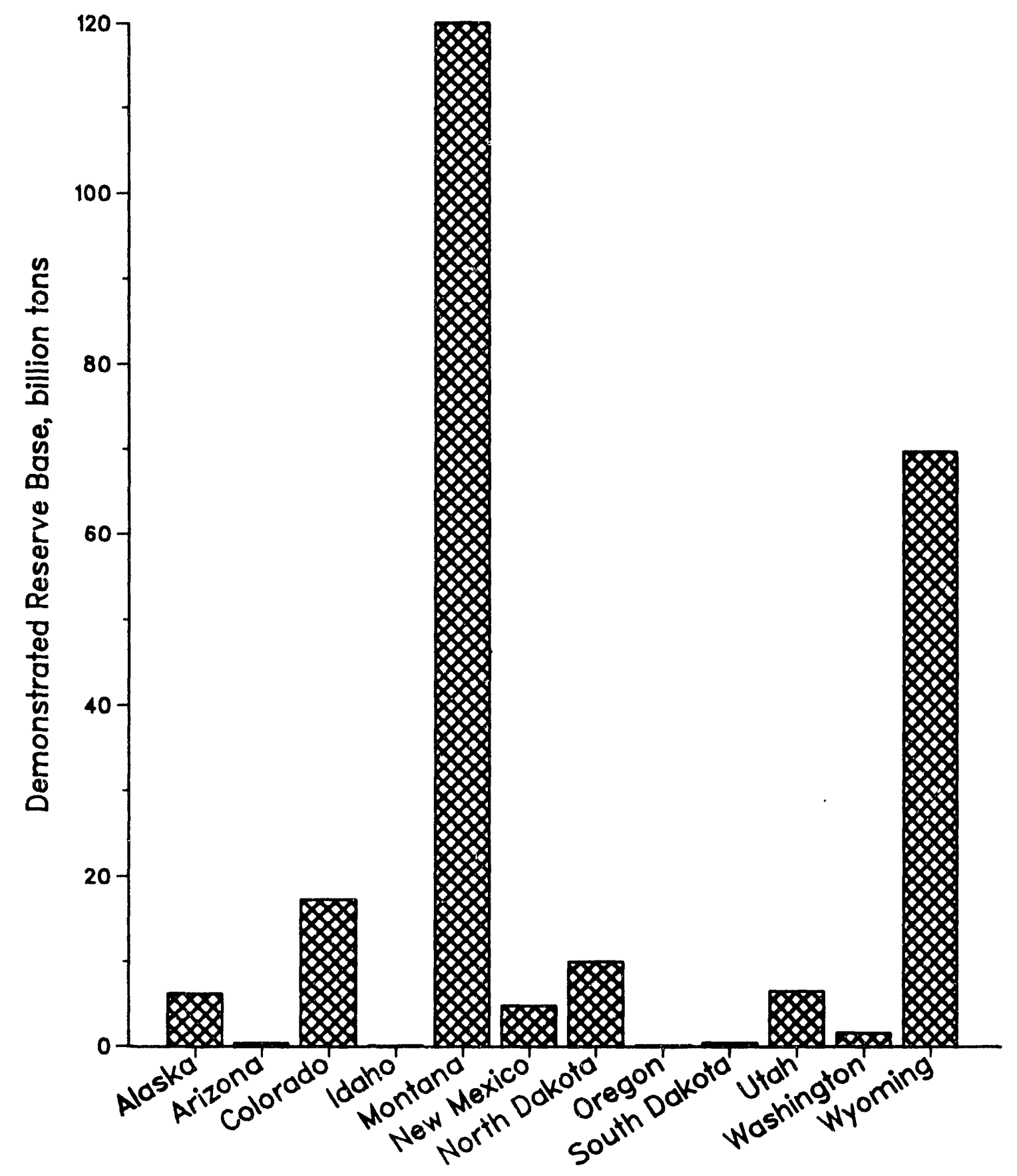

Figure 2. Distribution of Western Coal Denonstrated Reserve Base by state 


\section{Classification by Rank}

classification by rank is essentially a process whereby coals are grouped with respect to their degree of metamorphism in the natural series from lignite to anthracite. Coal begins this metamorphosis as vegetable matter and ends as essentially pure carbon. Generally, anthracites are older coals, whereas lignites are younger. Volatile matter, fixed carbon, inherent sed moisture, and oxygen are all indicative of rank, but no one item completely defines it.

The ASTM classification by rank is based on fixed carbon and caloric value calculated on a mineral-matter-free basis. older coals are classified according to amount of fixed carbon on a dry, mineral-matterfree basis, whereas younger coals are classified according to heat value on a moist, mineral-matter-free basis. classification by rank is useful for determining the value of coal for a given application. It is also useful for specifying and selecting burning and handling equipment. The rank of the intended fuel is important in the design and arrangement of heat transfer surfaces within boilers. Specifications used to classify coal by rank are listed in Table 1 .

Across the western region, coals ranging in rank from anthracite to lignite are represented. Many of these coals are well represented in other areas of the country, having been successfully beneficiated and used for over a century. These coals, when located in the West, share some of the problems associated with the lower rank coals, which are more characteristic of the area. In an effort to characterize the western coal reserve, the uniqueness of various coal properties as they relate to occurrences in the west will be examined. The relative significance of the various ranks of coal in the western area, with regard to what portion of the demonstrated reserve base and what portion of the actual coal production each represents, will be considered.

Small reserves of anthracite totalling about 27.8 million tons are found in the states of Colorado and New Mexico. The demonstrated reserve of anthracite represents only about 0.012 percent of the reserve of western coal and only about 0.4 percent of the national anthracite reserve, the bulk of which is located in the Appalachian region. obviously, from a purely quantitative standpoint, anthracite coals are of little significance for determining the characteristics of the western coal reserve. Anthracite preparation techniques are well established and have been successfully employed for nearly a century; therefore, for the purpose of this report, anthracite will not be considered further.

Demonstrated reserves of bituminous coal in the western area total some 24,740 million tons. This represents about 10.5 percent of the western demonstrated coal reserve, or about 10 percent of the national reserve of bituminous coal. Although bituminous coals represent only a small portion of the western reserve, they are widely distributed throughout the region and are of considerable significance in the states of Colorado and Utah. Bituminous coals represent about 50\% and 1008 of these state's 1982 demonstrated reserve base, respectively. Nearly 908 of the western reserve bituminous coal is mineable only by underground methods. 


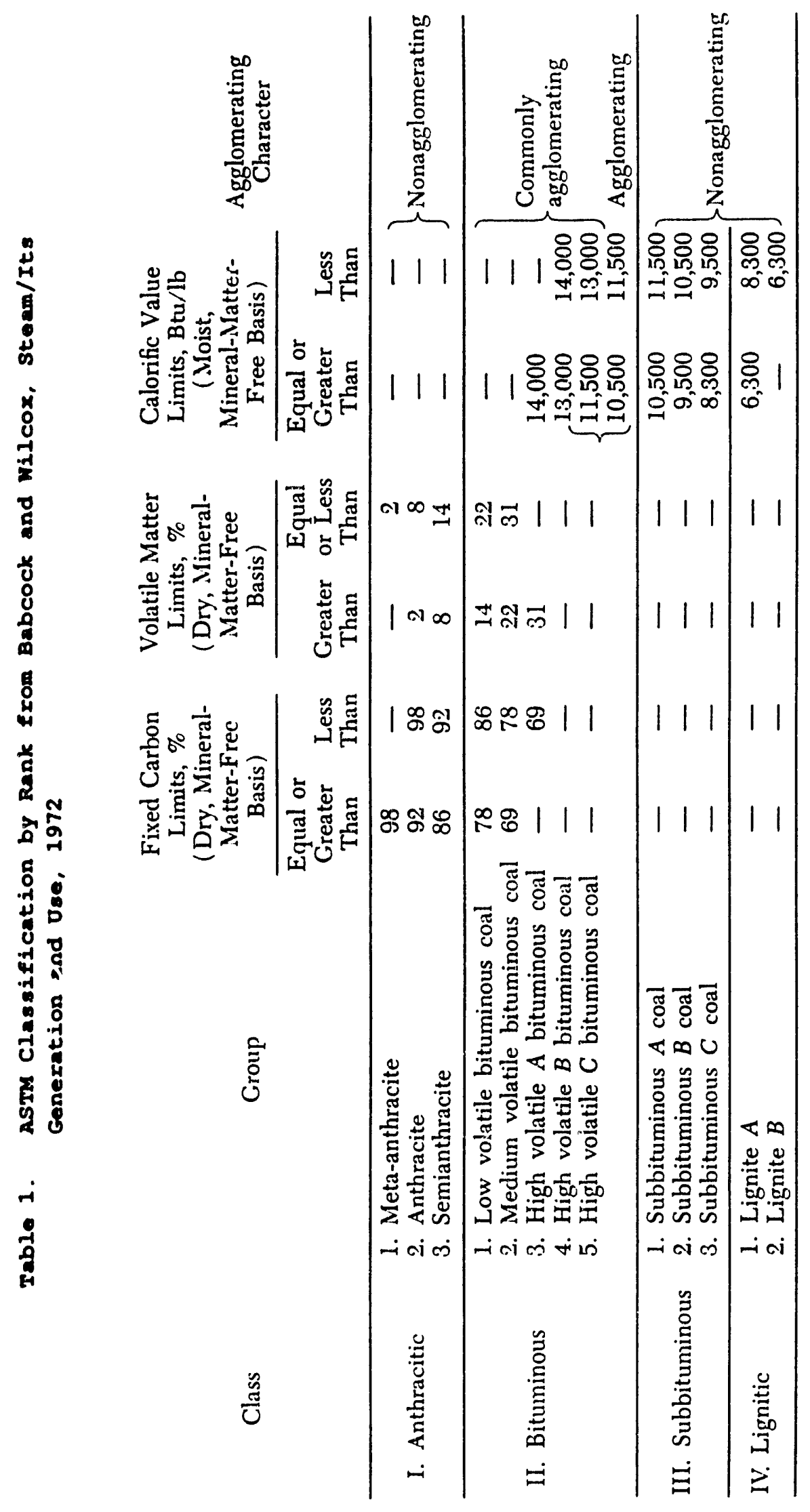


The bituminous coals of the West are very similar to their eastern counterparts, with the most common bituminous preparation techniques (sizing, washing, dewatering) being applicable to both. The degree of preparation to which bituminous coals are subjected is generally determined by the ash content from a given mine and the use to which the coal is put. Coal upgrading decisions for bituminous coals are site specific, and generalizations about cleaning are inherently inaccurate.

The most significant problem shared by bituminous and lower ranked coals of the region is their distance from the major coal markets. Transport distance is a factor that commonly favors a greater degree of beneficiation, but this determination must be made on an individual-case basis. The relative decrease in transport costs must be weighed against increased preparation costs. It is not possible to establish a generalized preparation scheme for western bituminous coals.

Subbituminous coals constitute the vast majority of the demonstrated reserve base and production for the western region. The 1982 demonstrated raserve of subbituminous coal in the western region was given at 181,650 million tons, nearly 778 of the total western coal reserve. The demonstrated reserve base for Alaskan coal is mainly subbituminous in rank, with the identified resource following the same trend. It is quite obvious that the dominating rank for the western region is subbituminous. It is also significant to note that nearly all of the national reserve of subbituminous coal is located in the western region. The pie chart in Figure 3 illustrates the significance of subbituminous coal in the western reserve.

There were about 30,250 million tons of lignite in the western demonstrated reserve base in 1982. Lignites represent about 12.88 of the western reserve with extensive occurrence in Montana, Colorado, and North Dakota. The western region accounts for about $67 \%$ of the national lignite reserve with the bulk of the remainder located in Texas.

Lignites share many of the same problems associated with the western subbituminous cuals. They are higher in moisture and of lower heating value than subbituminous coals. Nearly all the lignite production in the western region has been in North Dakota with about 26 million tons mined in 1985. Lignite development has been limited to strip mining only those reserves with thin overburdens located close to power plants designed to use lignite fuel. There is no market available to the north in Canada or to the west in Montana where lignite of the same character is available (Keystone 1987). Markets to the east and south are limited by transportation costs on a per-Btu basis in competition with eastern bituminous coal and all rail-transported coals of the midwestern and western coal fields.

Preparations that enhance the competitive value of western subbituminous coals may be applicable to lignites. This is because each suffer from high moisture content, low heat value, and a tendency to decompose upon exposure, but each is benefited by low extraction costs and low sulfur content. Western lignites may require additional preparation in order to decrease sodium content that leads to excessive ash fouling and slagging problems in boilers. 


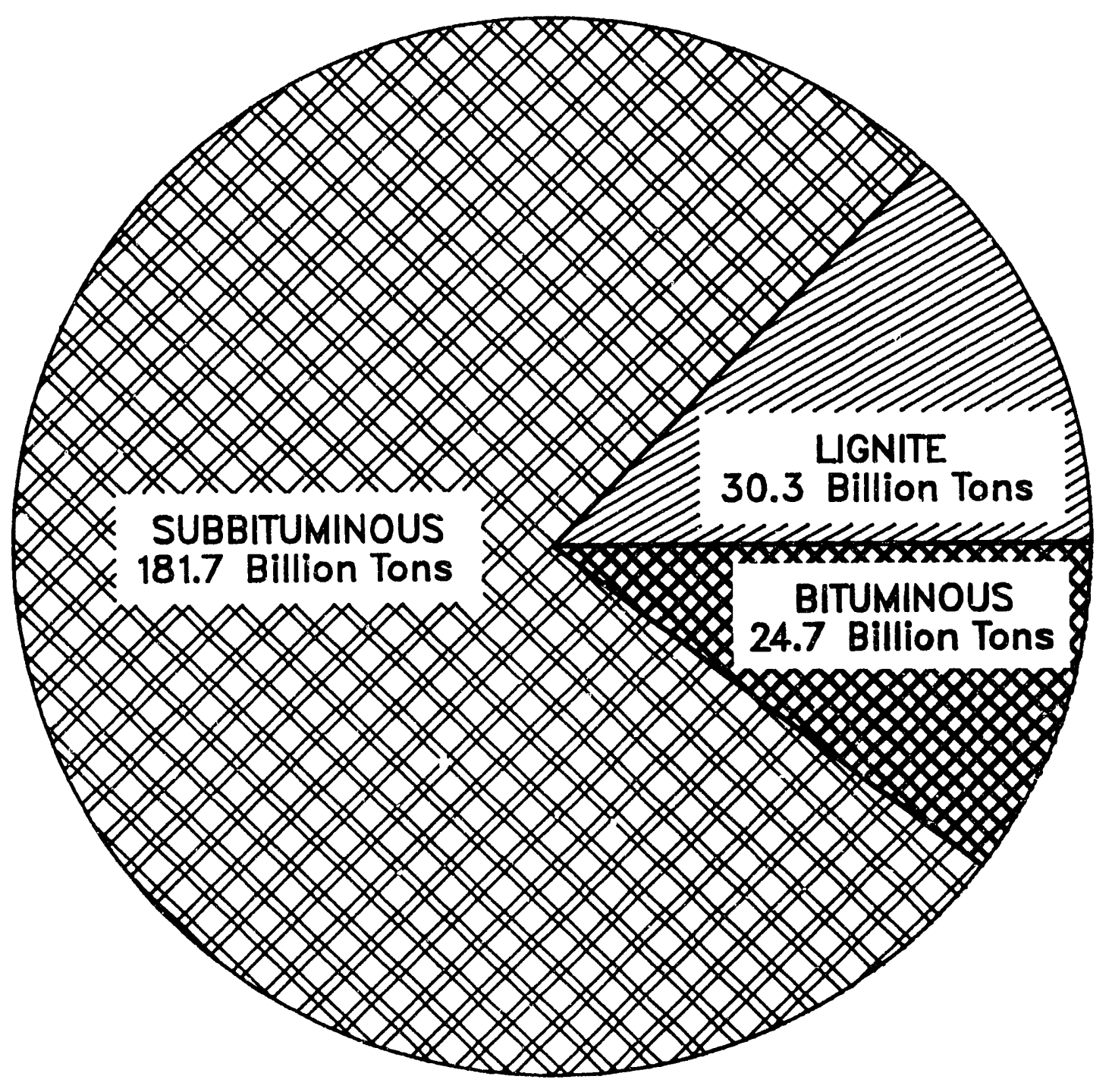

Figure 3. Western Coal by Rank 
On the basis of quantities available and economic significance, western coals can generally be characterized as low-rank coals dominated by subbituminous coals with considerable lignite reserves in a lower state of development. For the purpose of this report, western coal is considered to be abbituminous coal; however, coal preparation technologies that work well for subbituminous coals may also be applicable to lignites.

The ultimate decision as to what level of preparation is appropriate in a given instance will be influenced greatly by the final value of the product as it relates to potential markets. This is an area where lignitic and subbituminous coals may diverge substantially necessitating individual evaluation of preparation technologies.

Subbituminous coal is divided into three groups, designated A, B, and $C$, with moist, mineral-matter-free heating values of 10,500 to $11,5009,500$ to 10,500 and 8,300 to $9,500 \mathrm{Btu} / 1 \mathrm{~b}$, respectively. Lignites are divided into two groups on a moist, mineral-matter-free basis: lignite $A$ has heat values that range from 6,300 to $8,300 \mathrm{Btu} / \mathrm{lb}$, and lignite $B$ has heat values less than $6,300 \mathrm{Btu} / \mathrm{lb}$. Subbituminous and lignite coals are characteristically nonagglomerating. Both are weathering coals, exhibiting a strong tendency to disintegrate upon exposure to air, particularly under alternating wet and dry conditions.

The composition of the fixed carbon is essentially the same throughout the various ranks of coal; therefore, when taken on a mineral-matter-free basis, it is the volatile matter that accounts for the differences between ranks. The heating value of the volatile matter bears a direct relation to the properties of the pure coal and is perhaps its most important property as far as combustion is concerned. The volatile matter in lower rank coals is high in water and carbon dioxide and, consequently, low in heating value (Babcock and vilcox 1972 ).

\section{Proximate and Ultimate Analyseg}

Customarily, two different analyses (proximate and ultimate) are used for reporting the constituents of coal. By definition, the proximate analysis includes the determination of moisture, volatile matter, and ash and the calculation of fixed carbon by difference on an as-received basis. The ultimate analysis inciudes the determination of the weight percent of carbon, hydrogen, sulfur, nitrogen, and ash with the estimation of oxygen by difference for a dried coal sample (Babcock and Wilcox 1972). ASTM D 271 gives the standard laboratory procedures for making these analyses.

Table 2 lists the proximate and ultimate analyses of three selected western subbituminous coals. For comparison, a high-volatile bituminous coal from Illinois has also been included. The three western coals listed in Table 2 are by no means definitive of western coals. They were, however, chosen in an effort to select coals that can be considered as representative of the most exploitable portion of the reserve, as determined by current production levels. The potential economic benefit of preparation with regard to these coals was also considered. 
Table 2. Proximate and ultimate Analyses of selected Coals

\begin{tabular}{|c|c|c|c|c|}
\hline Analyses & $\begin{array}{l}\text { Eagle } \\
\text { Butte }\end{array}$ & $\begin{array}{l}\text { Big } \\
\text { sky }\end{array}$ & Uaibelli & $\begin{array}{c}\text { Illinois } \\
\text { No. } 6\end{array}$ \\
\hline \multicolumn{5}{|c|}{ Proximate, wt 8 as received } \\
\hline Fixed Carbon & 35.2 & 34.7 & 33.3 & 47.58 \\
\hline Ash & 4.7 & 8.3 & 8.36 & 10.84 \\
\hline Moisture & 29.2 & 26.0 & 26.4 & 9.00 \\
\hline \multicolumn{5}{|c|}{ Ultimate, wt of on dry basis } \\
\hline Carbon & 64.7 & 68.1 & 61.5 & 70.84 \\
\hline Hydrogen & 5.1 & 4.5 & 5.2 & 4.84 \\
\hline Nitrogen & 0.9 & 1.2 & 0.9 & 1.38 \\
\hline sulfur & 0.6 & 0.9 & 0.2 & 3.13 \\
\hline oxygen & 19.4 & 14.9 & 21.6 & 7.07 \\
\hline Ash & 6.6 & 10.5 & 10.6 & 11.91 \\
\hline \multicolumn{5}{|l|}{ Heating Value, } \\
\hline Btu/lb as received & 8,170 & 8,680 & 8,470 & 11,600 \\
\hline \multicolumn{5}{|l|}{ Heating Value, } \\
\hline Btu/lb dry basis & 11,540 & 11,730 & 11,508 & 12,747 \\
\hline
\end{tabular}

The Eagle Butte mine is located in Campbell County, Wyoming; this is part of the powder River coal Basin in the Northern Great plains Province designated by the U.S. Geological survey (Glass 1983). The Eagle Butte mine is strip mining coal from the wyodak-Anderson seam. This massive seam is generally 50 to 100 feet thick and is surface mineable over a distance of about $120 \mathrm{miles}$. It has been estimated that the seam contains at least 15 billion tons of strippable coal at depths to 200 feet. Wyodak-Anderson contains the largest tonnage in a single continuous coal bed anywhere in the United states (EPRI 1980).

The Big Sky mine is located at Colstrip, Montana; mining occurs in the Rosebud and McKay seams of the Powder River Basin. The Powder River Basin accounts for over 908 of Montana's total coal production (Keystone 1987). Coal is shipped from the Big sky mine by unit train some 800 miles to power plants in Minnesota.

The Usibelli coal mine is located near Healy, Alaska; coal of the Nenana Basin is strip mined. Alaska has seen only limited coal production; however, its great reserves and unique situation with regard to market locations and market potential make Alaskan coals prime candidates for upgrading. Alaskan coals are currently either consumed in-state or exported to Korea. Both uses involve transportation over considerable distances, and both represent significant new markets.

The increasing demand for low-sulfur coals in the Pacific Rim countries and increasing industrialization in Alaska are creating tremendous new markets that Alaskan coals are in the best position to serve. Transportation costs will be so large a part of the total energy dollar that only premium fuels will be competitive in these markets. 
Table 2 shows that the most significant differences between western and eastern coals are in moisture, fixed carbon, and sulfur content. The western subbituminous coals clearly suffer from a high moisture content, which depresses the heating value, but are benefited by a much lower sulfur level compared with Illinois No. 6 coal. It can be seen that on a dry basis the heating value of western coals approaches that of this midwestern coal.

\section{Moisture}

Western subbituminous and lignite coals are high-moisture coals. Moisture content of the Powder River Basin coals and subbituminous coals of the Green River region generally ranges between 20-308 on an asreceived basis (Keystone 1987). Moisture content of lignites from the Fort Union region of western North Dakota and eastern Montana ranges from 30-458. An average of lignite mine samples from 212 locations shows that the as-received moisture is 37.2 percent by weight (Gronhovd et al. 1982).

High moisture content is a very significant characteristic of western coal that affects many aspects of its use. Moisture is shipped at the same rate per ton as the coal. With transportation costs being a primary use-limiting factor for western coal, the importance of this factor can be readily seen. High moisture content is responsible for many handling problems such as freezing in rail cars and impeding the flow in conveyor systems, bins, chutes, and feeders.

High moisture content necessitates high primary air temperatures for drying in the mills for pulverization. Pulverizer throughput is limited by the capacity of the hot-air source (Gronhovd et al. 1982) and maximum pulverizer outlet temperature. Pulverizer capacity decreases as moisture content increases. Boilers operating on high-moisture coals require more pulverizer capacity per Btu than those burning low-moisture bituminous coals.

Moisture in coal represents a noncombustible constituent of the boiler fuel at the power plant. Heat is wasted in evaporating and raising the temperature of the water to the oxit gas temperature. Increased water levels in the exhaust gas necessitate higher gas exit temperatures to prevent sulfuric acid condensate from forming in the air heater. A decrease of 18 of total coal moisture increases thermal efficiency by about 0.18 . Leonard and Mitchell (1968) state this another way, "It is estimated that for each percent moisture over four or five the power plant capacity drops about $1000 \mathrm{kw}$."

Thus, high moisture in coal not only affects transportation costs but also can have detrimental effects on various boiler components and overall boiler efficiency. Components that can be adversely affected include pulverizers, downspouts, air heaters, and forced-draft fans. 


\section{Ash Characteristics}

Another factor of great importance in determining the use of a given coal is the quantity and composition of combustion residues broadly known as ash. Ash is derived from the mineral matter associated with coal-forming plants and from inorganic constituents that are added to the coal deposits from outside sources during or following coal formation. Ash content and composition can vary widely among coals from different parts of the country, from different seams, from different parts of the same seam, and even from the same mine.

Coals are classified into two groups according to the constituents of their ashes. Bituminous-type ash is defined as an ash having more $\mathrm{Fe}_{2} \mathrm{O}_{3}$ than CaO plus Mgo. Lignite-type ash is defined as ash having more $\mathrm{CaO}$ plus MgO than $\mathrm{Fe}_{2} \mathrm{O}_{3}$ (Babcock and Wilcox 1972). The ashes of western coal are typically lignite type.

The slagging (depositing of slag through formation of a molten phase on furnace walls) and fouling (formation of deposits on tubes in gas passages) characteristics of coal ash are of major concern to boiler designers and operators. Ash fouling of the heat transfer surfaces is the most serious operating problem of boilers fired on low-rank western U.S. coals (Gronhovd et al. 1982). Corrosion and erosion of superheater and reheater tubes is also attributable to various ash properties. However, these problems have been mitigated by improved boiler designs and are not specific to western coal combustion.

Table 3 lists the mineral analyses of ash from the four coals featured in Table 2. The analyses in Table 3 should in no way be construed as representative of a typical western coal because of the high degree of variability in coal noted earlier. These analyses are included only as an example to illustrate the variability of ash and the difference between bituminous and lignite-type ashes.

Table 3. Mineral Analyses of Ash of Selected Coal:

\begin{tabular}{lccc}
\hline & Eagle Butte & Usibelli & $\begin{array}{c}\text { Illinois } \\
\text { No. }\end{array}$ \\
\hline $\mathrm{Ash}$, 8 dry basis & & & 11.9 \\
$\mathrm{SiO}_{2}$ & 6.6 & 10.64 & 47.52 \\
$\mathrm{Al}_{2} \mathrm{O}_{3}$ & 23.0 & 38.61 & 17.87 \\
$\mathrm{TiO}_{2}$ & 14.0 & 16.97 & 0.78 \\
$\mathrm{Fe}_{2} \mathrm{O}_{3}$ & 1.40 & 0.81 & 20.13 \\
$\mathrm{CaO}_{\mathrm{MgO}}$ & 3.60 & 7.12 & 5.75 \\
$\mathrm{Na}_{2} \mathrm{O}$ & 23.0 & 23.75 & 1.02 \\
$\mathrm{~K}_{2} \mathrm{O}$ & 3.94 & 3.54 & 0.36 \\
$\mathrm{SO}_{3}$ & 1.50 & 0.66 & 1.77 \\
\hline
\end{tabular}


Research into the fouling properties of various coals has been carried out for many years. Research conducted by the Babcock and wilcox Company prior to 1955 indicated that the sintered strength of the ash deposit is of prime concern, whereas the ash fusion temperature bears little relation to the tendency to form bonded deposits. They determined that high coal-alkali content could be associated with high strength fly ash. A fouling index was established using total alkali content in the coal as a criterion for dividing coal into three categories. Alkali contents less than 0.48 were classified as low fouling, between 0.48 and 0.68 as medium fouling, and above 0.68 as high fouling.

Extensive testing with a wide variety of domestic and foreign coals demonstrated that sodium is the most important single factor affecting ash fouling. Potassium, which was included in alkali fouling indices, has no perceptible effect on ash sintered strength. Water-soluble sodium, which corresponds well with vaporized sodium in combustion, has a major effect on the sintered strength of the ash. Washing with hard water significantly reduced the sintered strength of the fly ash and, thus, reduced fouling (Babcock and wilcox 1972).

Though sodium is an important factor in determining the degree of fouling likely from a particular coal, its effects tend to be mitigated by high levels of calcium and magnesium. Testing of several lignites with ash of high alkali content (CaO, Mgo, $\mathrm{Na}_{2} \mathrm{O}, \mathrm{K}_{2} \mathrm{O}$ ) shows that, although fly ash sintering may take place at a relatively low temperature, the sintered strength of the ash remains low regardless of fouling tendency (Babcock and Wilcox 1972). The alkali constituents of the ash react with sulfur dioxide, forming sulfates. The sulfate bond is probably responsible for the low sintered strength of the ash.

Western coals characteristically contain high levels of alkali such as calcium, magnesium, and sodium. Western coal ash content is typically between 4 and 10 percent. Iron oxides are generally lower in western coal ashes than in eastern ashes. Ash fusion temperatures are similar to those of high-volatile bituminous coals.

\section{Fixed Carbon and Volatile Matter}

When classifying coal by rank, the volatile matter is defined as the products, other than moisture, given off when the coal is heated according to the prescribed method. Fixed carbon is the solid residue minus the ash that is obtained in the same heating process. on the dry ash-free basis, volatile matter plus fixed carbon equals 100 percent (Lowry 1945).

Fixed carbon is assumed to have a constant calorific value per unit (Lowry 1945) that is not affected by the rank of the parent coal. Thus, when taken on a pure coal basis (moisture and mineral-matter free), it is the variability of the volatile matter that accounts for the differences between pure coals. Stated another way, the variable constituents of coals can be considered to be concentrated in the volatile matter (Babcock and Wilcox 1972). 
since the conversion of carbohydrates to hydrocarbons has not progressed as far as in the higher rank coals, the volatile mat+e: of western low-rank coals is generally higher in oxygen content than that of the higher rank coals. The heating value of the volatile matter is, perhaps, its most important property as far as combustion is concerned. Heating value bears a direct relationship to the properties of the pure coal from which it was derived. The volatile matter of low-rank coals is relatively high in water and carbon dioxide and, consequently, lower in heating value compared with higher rank coals, which are relatively high in hydrocarbons such as methane (Babcock and wilcox 1972).

\section{Sulfux}

The quantity of sulfur in fuel has become more important to operators of boilers and power plants because of increasing concerns over sulfur dioxide emissions. Indeed, concern over sulfur emissions was a major factor in the phenomenal growth of the western coal industry in the 1970s.

The sulfur content of western coals is quite variable, and both high- and low-sulfur coals occur throughout the region. Published analyses of Wyoming coals (as an example) generally highlight the lower sulfur coals; however, some coals of relatively high sulfur content are known in the state (Keystone 1987). Selective mining of lower sulfur coals in wyoming results in an average of about 0.58 sulfur for mined coals with sulfur rarely exceeding 18 on an as-received basis.

In studies of Wyoming's lower sulfur coals, the sulfate form of sulfur averages less than 0.038 ( $3-58$ of the total sulfur); the pyritic form averages less than 0.28 (25-298 of the total sulfur); and the organic form averages less than 0.478 (70-728 of the total sulfur). sulfate sulfur, or that portion of the total sulfur that can be extracted by treatment with hydrochloric acid, is commonly only of minor importance. Pyritic sulfur $\left(\mathrm{FeS}_{2}\right)$ is the form most easily extracted by conventional cleaning methods because it has a much higher specific gravity (4.89-5.03) than coal (1.2-1.8). Organic sulfur is chemically bound to the coal and, thus, cannot be removed by physical methods.

The low percentage of pyritic sulfur, compared with the percentage of organic sulfur in western coals, makes conventional cleaning methods used on eastern bituminous coals of little value for reducing sulfur in western coals. For a typical coal produced in wyoming, for example, total removal of all pyritic sulfur will result in only a 308 reduction in total sulfur (Glass 1982). A similar cleaning of Illinois No. 6 coal can remove as much as 608 of the total sulfur.

\section{Heating Value}

By far the most important use of western coals is direct combustion producing steam for electric power generation. The heating value of a ccal is a direct measure of its energy value and, as such, is most inportant in determining its value as a fuel. Heating values are determined in the laboratory using an oxygen bomb calorimeter under specified conditions. 
Gross (hjgh) heating value is defined as the heat released from combustion of a unit quantity of fuel. The products are in the form of ash; liquid water; and gaseous $\mathrm{CO}_{2}, \mathrm{sO}_{2}$, and $\mathrm{N}_{2}$. Net (low) heating value is calculated from the gross heating value by deducting 1,020 Btu/lb of moisture derived from the unit quantity of fuel. Both the moisture that results as a combustion product and the moisture that was originally present in the fuel are included in the deduction (Babcock and Wilcox 1972).

The heat value of a fuel is expressed in units of Btu/lb with the Btu being the standard unit of heat and the pound being the standard unit of mass in the English system. The gross (high) heating value is used in the United states for reporting coal analyses and the comparison of different coals.

Western coals generally exhibit low heating values commensurate with their typical low rank. However, heat values vary widely throughout the region, and examples of both low and high heating value coals are available. Heating values of the low-rank coals, by definition, range between 8,300 and $11,500 \mathrm{Btu} / \mathrm{lb}$ for the subbituminous coals and less than $8,300 \mathrm{Btu} / 1 \mathrm{~b}$ for lignites.

The typically low heating values of western coals have a significant effect on the design and operation of combustion equipment. significantly greater quantities of fuel are required for a given ateam or electric power production rate when using a low-heat-value fuel. In order to handle the increased fuel volume, the number and size of pulverizer mills must be increased, and a larger furnace is required to maintain a given energy output. Essentially all ancillary process equipment must be increased in size to handle the increased volume of their respective streams. If boilers designed for the use of higherheat-value fuel are converted to use of low-rank coals, a significant derating of output is commonly required (Gronhovd et al. 1982).

\section{Grindability}

Grindability is a term used to express the ease of pulverizing a coal. The Hardgrove grindability index compares a sample to a standard coal chosen as 100 grindability, giving a numerical value that may be used to compare the relative ease of grinding various coals (Babcock and wilcox 1972). Grindability values below 100 indicate a coal that is more difficult to grind than the standard, whereas numbers above 100 indicate easier grinding. ASTM standard D 409 describes the method of testing used to determine the grindability index of a given coal.

The majority of western coal is burned in pulverized-coal-fired (pc) furnaces. The coal is ground into fine particles, transported to the burner in a stream of air, and completely combusted with a minimum of excess air. The grindability index of the coal is a factor used to determine the number and capacity of the pulverizers. For example, a pulverizer designed to generate a ground coal, 708 of which will pass through a 200-mesh sieve when grinding a coal of 50 Hardgrove grindability index, will suffer a 208 capacity reduction when grinding a coal with a Hardgrove grindability index of 40 (Babcock and wilcox $1972)$. 
The feed coal properties that most significantly affect grindability are moisture content and Hardgrove grindability index. High moisture content of the pulverizer feed greatly decreases pulverizer capacity, so much so that a modified ASTM D 409 procedure is used for low-rank coals. The modified procedure determines grindability at several moisture levels. Even the modified procedure has proved inaccurate for some lignites.

A fair, although not precise, correlation exists between coal rank and grindability. Figure 4 depicts the variation in Hardgrove grindability index as a function of volatile matter and rank (Berkowitz 1979). Anthracites and lignites are the most difficult coals to grind, whereas low-volatile bituminous coals grind most easily. Generally, western coals are low-rank coals and, as such, are more difficult to grind than eastern bituminous coals.

Hardgrove test data are markedly affected by the temperature and moisture content of the sample. Plastic deformation of small particles may also influence Hardgrove test data. Deformed small particles adhere strongly to each other forming aggregates that contribute to the progressive decrease in Hardgrove grindability as carbon content decreases below about 858 (Berkowitz 1979).

\section{Reactivity}

Low-rank coals tend to be more reactive than higher rank coals. This increase in reactivity can be explained, in part, by the higher level of organically bound oxygen and increased internal surface area typical of lower rank coals. Combustion heat causes a dissociation of the oxygen from the organic matrix leaving reactive sites for combustion. Higher levels of organically bound oxygen create a greater number of such reactive sites. This, as concerns combustion, creates a more reactive coal (Gronhovd et al. 1982).

The higher reactivity of western coals allows coarser grind from pulverizers (compared with bituminous coals) while still maintaining complete carbon burnout in pulverized combustion systems. More reactive coals are also easier to ignite than bituminous coals leading to work on direct ignition systems. This may eliminate the need for oil ignition in pulverized combustion with consequent fuel oil savings. Low-rank coals are also generally more reactive in gasification reactions.

The higher reactivity of western coals also has a negative side because it is a significant factor in spontaneous heating during delivery, storage, and handling. Low-rank coals also exhibit a greater tendency toward product degradation due to oxidation during storage compared with bituminous coal. 


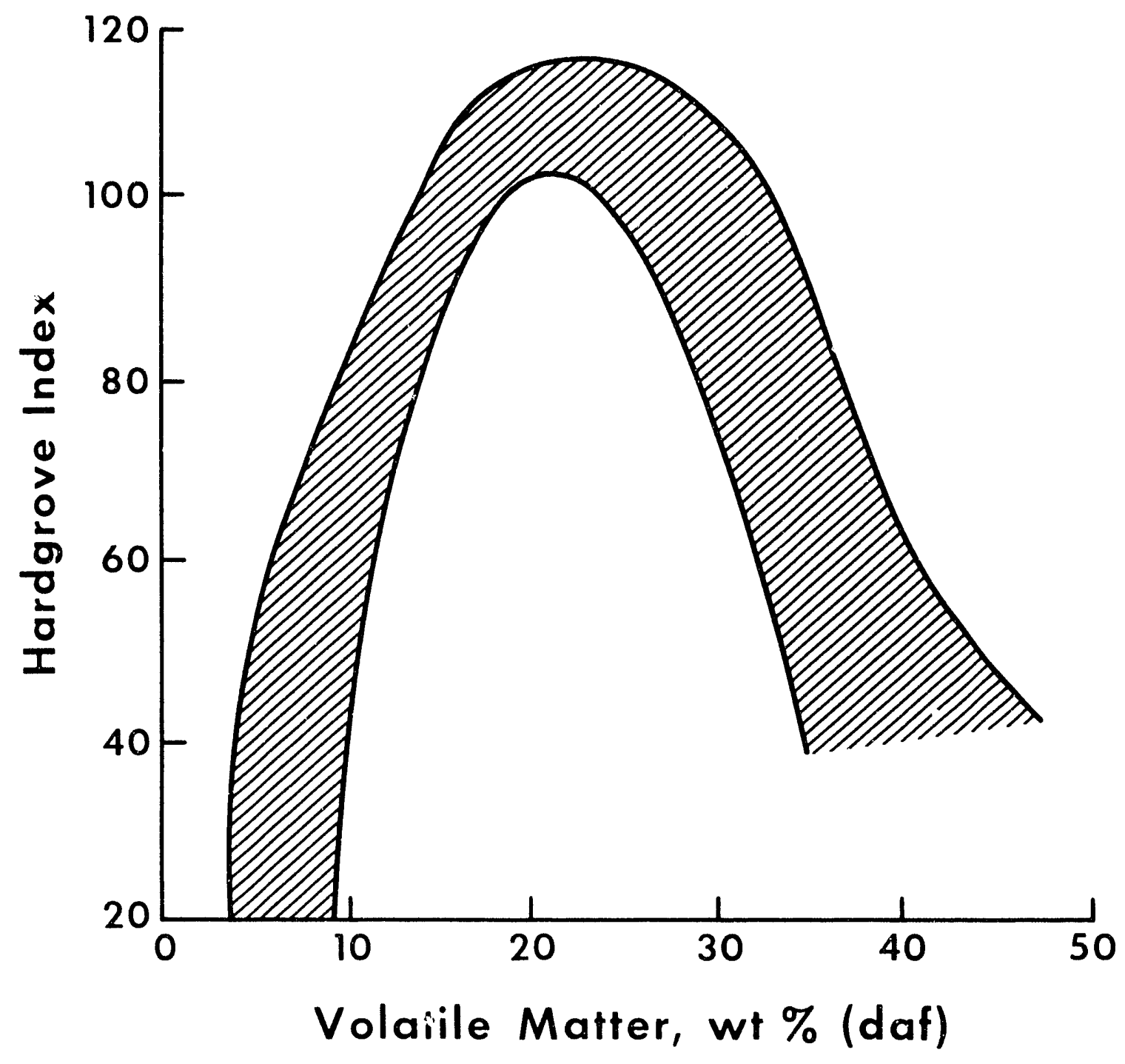

Figure 4. Variability of the Hardgrove Grindability Index with Volatile Matter Content (Rank) 


\section{Agglomeration and Westhering}

Certain bituminous coals pass through a transient plastic state in which they soften, swell, and finally resolidify into a more or less distended cellular mass when heated. This property is referred to as caking or agglomerating and is of prime importance in the production of metallurgical coke. Coals that do not become plastic upon heating form a weakly coherent or noncoherent mass known as char when heated and are referred to as noncaking coals (Berkowitz 1979).

Low-rank coals do not go through a plastic stage when heated and, thus, do not tend to form an agglomerated mass. Western coals are typically low-rank nonagglomerating coals. When combusted, the surface area-to-mass ratio does not tend to decrease (due to particle agglomeration) as it does with agglomerating coals. Therefore, a coarser grind is usable in pulverized combustion systems when burning low-rank coals (Gronhovd et al. 1982).

The tendency for a coal to disintegrate upon exposure to weather, particularly when alternately wetted and dried or subjected to hot sunshine, is referred to as weathering or slacking. Lignites slack very readily; subbituminous coals slack to some extent but less than lignites; and bituminous coals are only mildly affected by weathering (Leonard and Mitchell 1968).

The weathering character of low-rank coals tends to increase potential fugitive-dust emission problems and product degradation via surface oxidation due to continual formation of new surface area. Increased care must be used in dust control at facilities using and storing low-rank coals. The slacking tendency of low-rank coals can be advantageous in pulverized combustion systems where partial drying in or before the mills increases grindability of the coal with a consequent increase in pulverizer capacity.

\section{Extraction}

The first step in the use of any coal. is mining or extraction from the ground. The identified resource of U.S. low-rank coal is over 1 trillion tons, and approximately 108 of this is classified as the strippable reserve base. This portion of the resource is of the greatest immediate interest because virtually all low-rank coal currently produced in the United States is surface mined (Gronhovd et al. 1982). The low heating value and long transportation distances associated with western coals necessitate a highly efficient, low-cost extraction method to be competitive with higher rank coals that are located closer to the markets.

Although the properties of low-rank coals have little effect on the mining operation (aside from necessitating the most economical extraction possible), the mining operation does contribute to the properties of the coal. Surface mined coals are generally cleaner; they contain less debris from the mining operation and fewer inclusions of noncoal mineral matter than coals extracted from underground mines. 
Extremely thick seams with little inclination also increase the cleanliness of western subbituminous coals. Minimal contamination from the mining process and geologic conditions are largely responsible for the fact that almost none of the western subbituminous coal production requires washing, whereas over one-half the eastern bituminous coal production is washed.

\section{Surary of Hestern Coal Characteristics}

- Mainly subbituminous and lignite (low rank)

- Low heating value (6,300-10,000 Btu/1b)

- High moisture (12-308)

- Low sulfur (typically less than 18)

- Most sulfur as organic sulfur

- Lignite-type ash containing high levels of alkalis

- Nonagglomerating

- Weathering

- Highly reactive

- High volatile content

- Low heating value of volatile matter

- surface mined from relatively thick seams

- Frequently transported over long distances

- Mainly used as fuel for electric power generation

\section{THE U.S. COAL MARKET}

The U.S. coal market can be conveniently divided into four sectors: electric utilities, industrial/retail, coking coal, and export coal. By far the most important is the electric utilities sector, which consumed about 788 of total U.S. coal production in 1987 . About 868 of domestic consumption is by utilities; in 1987, utilities consumed about 718 million tons of coal. Coal consumption by the electric utilities increased steadily through the last decade using an ever increasing share of the domestic production.

Several large industries consume considerable quantities of steam coal. In the United States, coal is used to generate process steam and heat in many mineral-related industries and in the chemical, paper, food, fertilizer, and textile industries. Large quantities of coal are used by the cement industry, and many kilns were converted to coal firing in the last decade. Independent power producers and cogenerators are beginning to account for a greater share of the industrial coal market.

Retail sales of coal for residential and commercial space heating have declined to a level between 6.5 and $9.5 \mathrm{million}$ tons per year where they have remained since 1975. Coal use for home heating has declined leaving boilers in large commercial and government buildings as the primary consumer in this market area. In 1987, the industrial sector consumed about 82 million tons of coal. This accounts for nearly 108 of domestic consumption or about 98 of the coal produced in the united states. The production of metallurgical coke and its portion of U.S. coal consumption has been declining for quite some time. In the period between 1980 and 1987 , consumption in this market has decreased from 67 million tons per year to only 37 million tons per year. 
Modern steel production methods use less coal per ton of steel, and the demand for steel in the united states has been declining. The use of pulverized coal injection in blast furnaces, a process that does not require coking-quality coal, has resulted in declining coking coal sales. Demand for coking coal seems to have stabilized at around 37-38 million tons per year; this accounts for about 4.58 of the domestic coal market or about 48 of total U.S. coal production.

The United States exported about 80 million tons of coal in 1987 , which was about 98 of the total U.S. production. Currently, about 45 million tons of metallurgical coal is exported annually; the remaining exports are steam coal. U.S. coal is exported to South America, Western Europe, Asia, and Canada. Small quantities of coal are also imported to the United States and are destined primarily to Gulf coast markets.

\section{Projected Trends}

Continued growth is expected in the consumption of coal by electric utilities. National Coal Association (NCA) projections place consumption by electric utilities at about 872 million tons by the year 2000. These figures project a consumption increase of about 21.58 in this sector for an annual growth rate of about 1.58 .

A strong growth rate in the electric power industry in conjunction with some fuel switching has been largely responsible for the increase in coal consumption by electric utilities in the past decade. Although growth trends in electric power generation are not expected to be as strong in the next decade, growth in still expected at a rate of about 2.28 per year (Moody 1989).

The growth rate in coal consumption by electric utilities is expected to decline from that of the past decade. This is because of a slowdown in the conversion of boilers to coal firing and a decline in the construction of new coal-fired plants. Despite a declining growth rate, electric utilities are expected to increase their share of the domestic market to 888 of domestic coal consumption by 2000 .

Growth in coal-fired electric generation will be greatest in the southern United States, where nearly 608 of capacity additions are expected. Large increases in generation capacity are also projected in the Midwest; increases in both coal-fired and nuclear capacity are expected (Moody 1989). The East North Central region will remain the largest coal consuming region, but growth in this region is expected at only 18 per year through 2000 because of decreasing growth in generating capacity and increased nuclear and natural gas-fired capacity.

Growth in the industrial/retail market sector is projected through the year 2000. Coal sales are predicted to reach 91 million tons. Growth in industrial coal sales are expected to result from increasing coal use by nonutility generators (NUG) and cogenerators of electricity as a series of rulemaking by the Federal Energy Regulatory Commission (FERC) beging to increase competition in the generation of electricity. Coal consumption by NUGs is projected to increase from about 1 million tons per year in 1987 to 16 million tons per year by 2000 . About 258 of the NUG market will be fueled by coal. 
Increases in NUG are expected in the Northeast and southwest. These two regions will account for about 658 of Nug coal consumption by 2000 . Currently, the West and West South Central regions are most developed in NUG capacity.

Traditional industrial uses of coal are expected to decline in the next decade because of environmental considerations and increasing industrial use of natural gas. New source performance standards for industrial boilers are expected to have the effect of limiting additions of coal-fired industrial capacity. The emergence of fluidized-bed combustors and other clean coal technologies will help to offset declines in new coal-fired installations, but increasing availabil.ty of natural gas at competitive prices is likely to keep coal from increasing its share of the industrial fuels market.

Small increases in coal consumption in the chemicals and synthetic fuels industries are expected, but long lead times for development and construction will keep these industries from having a major impact on industrial coal sales before 2000. Coal use by other major industrial consumers (minerals processing, clay and glass, paper, and textiles) are expected to decline. The residential/commercial market is expected to decline slightly to about 6 million tons per year by 2000 .

Coal consumption in the metallurgical coke industry has declined steadily throughout the past two decades. In 1970, the coke industry consumed 97 million tons of coal; by 1980 , only 67 million tons were used. This use declined to only 38 million tons by 1990 . Consumption is projected to remain about steady or decline slightly to about 34 million tons by 2000 .

steel production per unit GNP has been declining because of increases in high-tech industries and declining steel use in the manufacturing and automobile industries. This trend is expected to continue through the next decade, resulting in lower demand for and production of steel. The use of steel production technologies that require less coal per ton of steel has increased throughout the past decade and will continue to do so, although at a slower rate, through the year 2000 .

Coke oven capacity in the United states is on the decline as coke plants age and are not replaced. The declining demand for steel and metallurgical coke has limited investment in new coke plants. This places an upper limit on potential domestic coke production.

The decreasing demand for U.S. steel, changing steel production methods, and limited coke oven capacity all combine to decrease the demand for coal by the metallurgical coke industry. However, the rate of decline should be much smaller in the coming decade than in the past two.

The markets for U.S. coal abroad are expected to increase, which will result in an increase in U.S. coal exports. International coal trade is projected to increase to 539 milition tons per year with the 
United states capturing about 21.58 of this market by 2000 . This will account for about 116 million tons of U.S. production. Exports of 116 million tons will represent a 458 increase over 1987 levels.

Metallurgical coal exports are projected to increase from 45 million tons in 1987 to 57 million tons by 2000 . One-half of this increase is expected to go to Brazil. Brazilian steel production is increasing, whereas their metallurgical coal production is declining.

Exports of steam-quality coal are projected to double by 2000 , and much of the increase will go to European markets. In Europe, large coal-fired generating capacity additions are currently underway. Privatization of the utility industry in the United Kingdom is expected to increase British use of imported steam coal.

Asia will increase its imports of steam coal as demand increases, but the NCA predicts that much of this new market will be filled by imports from China and Australia. Canadian imports of U.S. coal are expected to decline by about 2 million tons per year by 2000 .

In summary, the markets for U.S. coal will continue to grow through the next decade. Strongest growth will be in demand for steam coal by the electric utilities, particularly those in the southern united states. Industrial use of coal will increase, mainly because nonutility generators are entering the electric power market. Metallurgical coal use will decline slightly in the united states, but exports of metallurgical coal, will increase. Coal exports will increase by about 458 in the next decade with the bulk of the increase being steam coal for European markets.

\section{Western Subbituminous Coal Markets}

As with the overall U.S. coal market, the main consumers of western subbituminous coal are the electric utilities. The importance of electric utilities as a market for western coal can be illustrated. currently, 97.78 of wyoming coal production is used by electric utilities; whereas nationally, utilities consume only about 788 of total coal production.

This shifting of the market toward utility consumption is due mainly to the characteristics and location of western coal. There simply is not a large industrial base in the west; most of the traditional industrial coal users are located in the eastern United states. Western subbituminous coal is not suitable for conventional coking processes so almost no western coal is used in the metallurgical market. with the exception of Alaskan coal, westerr coal requires considerable overland transportation just to reach the nearest port. The high cost of getting western coal to port combined with the low heating value of the coal severely restrict export market potential.

Thus, the vast majority of western coal is purchased by electric utilities because no other significant market for the product exists. Western coal exports will be steam coal primarily for use by electric utilities abroad, though some industrial use in Asian Pacific Rim countries is expected. 
Use of western coal by electric utilities is projected to grow through the next decade, although not nearly as rapidly as it grew in the previous 15 years. Growth in generating capacity in the southern United states will increase the market for western coal, much of which is sold in the south. Utility consumption of western coal will also see some increase because of amended clean air legislation. production of western coal is projected to increase by 23.78 above the 1987 level with increased demand by electric utilities accounting for nearly all the production increase.

Western coal is used in such industries as mineral processing, cement manufacture, agricultural processing, and for cogeneration of electric power. The synthetic fuels industry and nonutility electric power production are both likely to grow as industrial consumers of western coal, but neither will consume significant quantities by 2000 . The percentage of western coal that is used industrially will decline as electric utilities consume a greater share of western production. Commercial and residential use of western coal will continue to consume only a very small percentage of production.

Generally, western subbituminous coal is unsuitable for coke production; only an insignificant percentage of western coal is used as metallurgical coal. There is some limited use of western coal in the metallurgical market. For example, a synthetic coke plant in wyoming owned by FMC Corporation uses a small quantity of western coal for producing a synthetic coke that is used in regional mineral processing.

Iron and steel production in the west is minimal and will not increase significantly in the next decade; therefore, regional demand for metallurgical coal will remain small. The portion of western coal that is used as metallurgical coal will decline in the next decade as more western coal is consumed by electric utilities.

The coal export market is not a major consumer of western subbituminous coals. Increasing demand for U.s. coal on the export market will have little effect on western coal markets because most of the increase is expected to go to European countries. Alaskan coal is in a good location for export to the Asian Pacific Rim. There, it will compete for market share with Chinese and Australian coals. Recent political events in China may help to improve Alaska's market position.

The map in Figure 5 and the chart in Figure 6 (adapted from Glass 1990) illustrate the marketing and distribution of wyoming coal. Although other western coals will have their own distribution patterns, the information for wyoming is indicative of trends in western coal marketing.

The significance of coal transportation distances can be clearly seen with Wyoming coal being marketed in 29 states. It is also notable that most Wyoming coal is consumed in the southern and central regions of the United states where electric-generating capacities are projected to increase in the next decade. Small quantities of this western coal are transported as far as the east and west coasts. Figure 6 shows the significance of rail transport in western coal marketing with nearly 938 of Wyoming's coal being transported by rail. Figure 6 also illustrates the dominance of the electric utilities in the western coal market. 


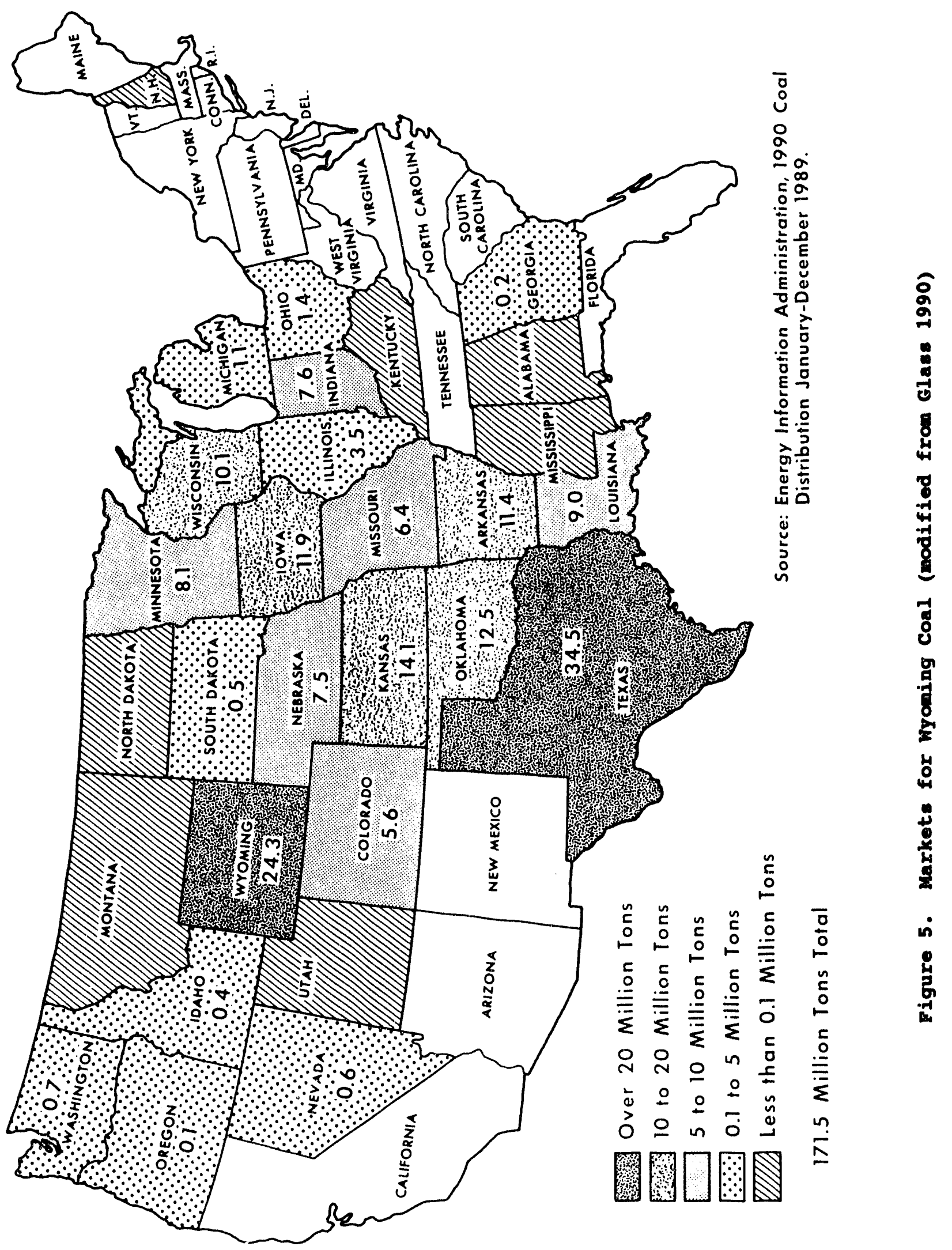




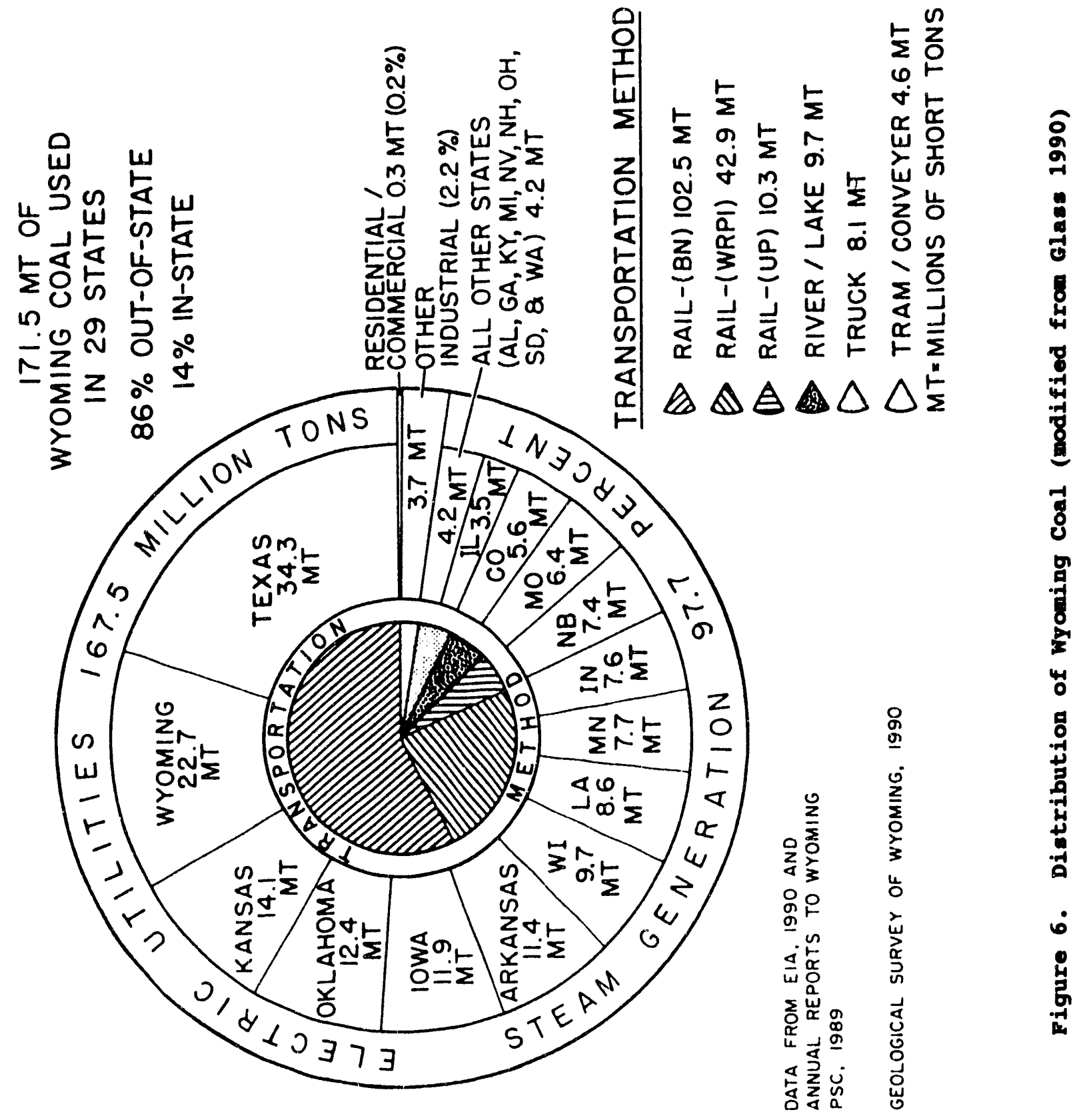


In summary, the only significant market for western subbituminous coal is electric utilities. Industrial use is limited by the low industrial density in the western region and by the inability of many industrial users to accept unit train shipments; this is a factor that significantly increases transportation costs. Coal conversion processes will begin to increase industrial use of western coal, but long lead times and other constraints such as limited water availability and permitting delays will limit their impact on the market in the next decade. Metallurgical use of western coal will remain insignificant due to the characteristics and location of the coal. Exports of western coal will increase as more western coal reaches Asian markets, but export coal will remain a small portion of the market through the next decade.

\section{Coal specifications for Electric Utilities}

Utilities set specifications for the fuel they will purchase. The maximum amount of ash, moisture, and sulfur are generally included along with the minimum heating value. Ash characteristics such as softening and fusion temperatures, ash slagging and fouling parameters, and slag viscosity may also be specified (Babcock and wilcox 1972). Coals that do not meet specifications must either be upgraded or sold elsewhere. The principal considerations when setting coal specifications are boiler design and, since the clean Air Act of 1970, pertinent air quality regulations. Amendments to the clean Air Act enacted in 1990 extend emissions restrictions to cover boilers not previously regulated. Air quality regulations are becoming increasingly significant in determining fuel specifications.

Nearly every aspect of boiler design is affected by the properties of the coal with which the boiler will operate. Things such as tube spacing, furnace size, location and size of heat exchange surfaces, number and location of soot-blowers, pulverizer capacity, and a host of other boiler design considerations are affected by the fuel characteristics (Babcock and Wilcox 1972).

Boilers are designed to operate efficiently on coals with characteristics falling within certain set limits. Generally, the broader the range of acceptable fuel characteristics, the greater the initial cost of the boiler. However, considering that the fuel bill for one year may equal the cost of the boiler, it is commonly preferable to invest more in equipment that can accommodate a rather wide range of coal characteristics. This allows the operator greater flexibility in purchasing fuel.

Although the boiler design may be able to accommodate a wide range of characteristics, operators find that a coal must not only be suitable to the equipment, but it must also be reasonably uniform. Uniformity of feed is perhaps the most important single factor contributing to efficient and economical boiler operation. Utilities, almost without exception, purchase coal on the basis of overall fuel economy, seeking the fuel with the lowest cost per million Btu on an as-consumed basis rather than on an as delivered basis (Leonard and Mitchell 1968). Since 1970, utilities have had to meet applicable requirements of the clean Air Act. The characteristics of the fuel that is used can significantly 
affect the cost of meeting emissions standards. Sulfur oxides emissions have been a primary consideration for utilities since the enactment of the clean Air Act and, thus, have a significant influence on coal specifications.

Less sulfur in the fuel produces lower quantities of sulfur oxides in the flue gas, which in turn, can mean lower flue gas cleaning costs. Flue gas cleaning can represent a very significant portion of the initial and operating costs of a modern coal-fired power plant. Flue gas desulfurization (FGD) systems can consume 5-158 of the power output of a plant and account for 20-308 of the cost of electricity produced (Schobert 1987). Reducing flue gas cleaning costs, including the cost of disposing of the residue from the cleanup system, has become a major consideration for electric utilities. The primary effect of emissions restrictions on coal specifications has been in decreasing the maximum acceptable sulfur content. Table 4 gives coal specifications of various electric utilities.

Table 4. 1982 Coal specifications of some Eastern utilities

\begin{tabular}{|c|c|c|c|c|c|}
\hline Utility & station & sulfur, 8 & Ash, \& & Moisture, 8 & Btu/lb \\
\hline \multicolumn{6}{|l|}{ Duquesne } \\
\hline \multirow[t]{3}{*}{ Light } & Cheswick & $1.4-1.6$ & 11 & 6 & 12,300 \\
\hline & Elrama & 2.5 & 18.0 & $5.7-5.8$ & 11,450 \\
\hline & Phillips & 2.3 & 15.5 & 5.5 & 11,800 \\
\hline PP\&I & Montour & 2.2 & 15.0 & 6.0 & 12,400 \\
\hline \multirow[t]{3}{*}{ TVA } & Colbert & 2.2 & 12.10 & 7.8 & 11,680 \\
\hline & Johnsonville & 2.3 & 9.80 & 10.30 & 11,600 \\
\hline & Paradise & 4.2 & 16.90 & 9.10 & 10,570 \\
\hline AECI & New Madrid & 4.0 & 12.0 & 15.0 & 10,500 \\
\hline \multirow[t]{3}{*}{ CPL } & Roxboro & & & & \\
\hline & Units $1,2,3$ & 1.4 & 15 & 8 & 12,000 \\
\hline & Roxboro Unit 4 & 0.7 & 15 & 8 & 12,000 \\
\hline \multirow[t]{2}{*}{ CILCP } & E.D. Edwards & & & & \\
\hline & Unit 3 & 0.7 & 15 & 8 & 12,400 \\
\hline \multirow[t]{2}{*}{ NEES } & Brayton Point & 1.57 & 10 & 8 & 13,000 \\
\hline & Average & 2.1 & 13.2 & 8.1 & 11,800 \\
\hline
\end{tabular}

Source: Hutton and Gould 1982

\section{Criteria for Upgrading Western Subbituminous Coal}

Various coal upgrading technologies are used to improve the marketability or increase the value of mine-run coal. Coal upgrading technologies have been developed to modify undesirable characteristics of the raw coal. Coal is upgraded to make the product more compatible with market specifications or to improve its quality and, thus, increase its value. The use of coal preparation technologies that upgrade coal quality has been increasing through the past decade. This increase in upgrading has been strongly influenced by the sulfur oxides emissions 
limitations imposed by clean air legislation. Preparation technologies have been used extensively to improve the quality of various eastern bituminous coals by reducing mineral-matter content with consequent reduction in sulfur associated with the mineral matter.

Upgrading technologies rely upon the separation and removal of impurities from the raw coal, thus creating a coal of higher purity and higher value. Two basic types of impurities are common in coal: ashforming mineral matter and moisture. Excess mineral matter and the sulfur associated with it are the most significant impurities in eastern bituminous coals. Excess moisture is the impurity of greatest significance in western subbituminous coal.

since 1975, the use of western coal by electric utilities has increased dramatically. Low sulfur content and low mine-mouth price make western coal a desirable fuel as utilities expand generation capacity under the emissions restrictions of the clean Air Act. Western coal is a natural fuel choice for utilities that are increasing generating capacity in the western United states, and clean air legislation has provided inroads for western coal into eastern markets.

Characteristics of western coal other than low sulfur and low cost enhance its desirability as a boiler fuel. Modern strip-mining techniques and extremely thick seams not only allow for low-cost extraction, but they also generate a coal with consistent properties and minimal dilution by mining debris. Much of the western coal reserve is low in mineral-matter content as well. Generally, western coal is a clean, low-sulfur coal.

Western coal characteristics that detract from its quality and value as a boiler fuel are primarily associated with its high moisture content, low heating value, and geographic location. The heating value of western coal is too low to meet coal specifications of many utilities, and its moisture content is too high. The great distance between mine and market also detract from the desirability of western coal.

Coal transportation costs for western coal can easily exceed the mine-mouth coal cost and add greatly to the delivered price of the coal. Coal transportation costs are negotiated on an individual basis, but an average of published costs shows that typical rates are between 1.5 and 2 cents per ton per mile. Thus, a one-thousand mile haul, about the distance from the Powder River Basin fields to st. Louis, Missouri, adds 15 to 20 dollars to the cost of each ton of coal. The importance of transportation costs in western coal marketing can be illustrated with figures from a recent coal sale by Amax Coal company from the Belle Ayr mine in the Powder River Basin coal field. The coal was sold for $\$ 4.05$ per ton F.O.B. with a delivered price in Fremont, Nebraska, of $\$ 13.85$ per ton (Glass 1990). In this instance, transportation costs represent over 718 of the delivered coal cost.

other characteristics of western coal that decrease its desirability as boiler fuel are grindability and reactivity. Western subbituminous coal does not grind as easily as many eastern bituminous coals. The lower grindability and low heating value of western coals require greater pulverizer capacity per million Btu. 
The high reactivity of western coals will allow a slightly coarser grind while still maintaining complete carbon burnout and can, thus, partially offset reduced pulverizer capacity. High reactivity also provides for easier ignition with a consequent savings in ignition oil use. The high reactivity of western coal also has its downside. High reactivity is associated with problems of oxidation and possible spontaneous ignition during handling, transportation, and storage of western coal.

The most detrimental characteristics of western coal are high moisture content, low heating value, and high transportation costs. Technologies used to upgrade western coal must be capable of improving these characteristics of the product. Because transportation costs are such a large portion of the delivered-coal cost, reductions in this area offer great pot intial for offsetting preparation costs.

\section{COAL PREPRRATIOA}

The purpose of coal preparation is to improve the quality of the raw coal or to make it suitable for a specific market (Babcock and wilcox 1972 ). In other words, coal preparation modifies certain characteristics of the raw coal and generates a more saleable product. Coal preparation technologies vary from simply crushing and screening to a specific size range to complex chemical treatments that can produce nearly pure coal.

Great diversity exists among the various coals of the United states. As mined, coal is a heterogeneous mixture of organic and inorganic materials, the relative proportions and compositions of which vary widely from region to region and mine to mine. Even within the same seam, a wide range of coal qualities exist. Efforts to generate a more uniform product, and gain a competitive edge for markets, was the original impetus behind the development of coal preparation technologies.

The generation of a more consistent, higher quality, and higher value product is still the reason behind all coal preparation. simply removing the coal from the ground does not necessarily guarantee a saleable product. Commonly, other steps are needed to create a product that will meet the demands of the consumer.

A great deal of coal preparation had its roots in the metallurgical coke business. Early in this industry, it was found that coal properties had a significant effect in the quality of the coke produced. Thus, the industry began setting specifications for the coals that they would buy. Coal producers adopted various preparation methods to meet the requirements of this premium narket. Western coals are generally not suitable for coke production; however, utilities, which constitute the major market for these coals, realize the importance of coal quality in the efficiency of their operation. As coal prices rose, the industry demands for quality also rose, and more steam coal began to be cleaned. 
Removing impurities from raw coal to upgrade the product is an expensive operation employed only through necessity. The coal industry uses upgrading methods for two reasons: (1) to increase its net income per ton of product and (2) to provide a steady outlet for its products (Leonard and Mitchell 1968). Net income can be increased by either decreasing production costs or increasing realization. Mines can use coal preparation to offset cost shortcomings in mining and hauling, thus, generating a higher value product and a greater realization.

The simplest and earliest forms of coal preparation amounted to removing the rocks and debris by hand and selecting coal of a secific size range either by hand or with screens. Selection by size was an important aspect of the earliest preparation practices because larger sized coal was required by the boilers of the day. Coal producers met this need by rejecting the fines at the mine (Leonard and Mitchell 1968 ).

Picking and sorting to a size that was compatible with the boilers being used is a nice example of one of the main reasons behind any coal preparation practice, that is, the generation of a fuel that meets the user's specifications. This is as pertinent today as it was a century ago. Boilers have changed over the years and so have their fuel specifications. However, if one wants to sell coal, one must supply a product that fills the user's needs.

The demand for lower sulfur fuels has been an important reason behind the current trend toward increased cleaning of eastern coals. The quantity of cleaned coal used by utilities has incseased significantly since 1978 (Deurbrouck 1985). The 1987 Reystone Coal Industry Manual reports that about 458 of the coal used by utilities in 1978 was cleaned, whereas in 1983 over 708 was cleaned. There are many reasons for this increase, but a primary reason has been presgure from environmental agencies to burn lower sulfur coals (Deurbrouck 1985).

Decreasing quality of raw coal has been another factor in the increase of coal cleaning (Hutton and Gould 1982). The last twenty years have seen a great increase in the amount of coal used for power generation. Rising oil prices in the early 1970s were a major factor in increasing coal consumption. Increasing demand and rising labor prices at the mine required operators to increase production per unit of 1 abor, making selective mining less desirable as a means of quality control (Leonard and Mitchell. 1968).

Increasing mechanization and the introduction of continuous mining machines have dramatically increased production, but the miner has much less control over the product loaded out. Efforts to reduce the impurities loaded in the mine typically increase mining costs. Generally, mine face cleaning is greatly reduced with the use of mechanical mining methods, and the widespread use of continuous mining has resulted in more impurities leaving the mine (Babcock and wilcox $1972)$.

Some of the best and most easily mined eastern coal has already been depleted; this added to the decline in coal quality. As coal quality declined, the demands of the market were taking an opposite direction. 
Air quality regulations became more stringent, and power plant operators became more aware of the effects of coal quality on overall efficiency. The coal industry met this problem by increasing the use of coal washing plants. Coul producers who could not meet increasingly demanding market specifications were forced to either look for new markets for their products, modify their raw coal so that it met specifications, or go out of business. To maintain a steady outlet for its products, the coal industry has turned increasingly toward the use of coal preparation plants as the most economical means of improving the quality of its product.

\section{Economice of Coal Proparation}

Once the requirements imposed by boiler design and emissions limitations have been met, there is still generally a wide range of coals that can be satisfactorily used by a specific consumer. The final choice of fuel depends primarily on economics (which fuel will produce steam at the lowest overall cost) including cost at the mine, shipment, storage, handling, and operating and maintenance costs.

Utilities have large capacity volume requirements an'l are generally in a position to select coal that will result in the lowsst overall cost per million Btu. Freight costs, which the utility pays, are given the utmost consideration when selecting steam coal (Leonard and Mitchell 1968). Utilities may find economic advantage in buying and cleaning a local coal rather than paying shipping costs on a more distant but higher quality coal.

Because of the variability of coal characteristics, the effects of coal cleaning cannot be generalized. For example, the ash fusion temperature of one coal may be lowered by cleaning, whereas that of another coal may be raised by cleaning. Some reduction iñ suifur is usually realized in coal cleaning. This is always a benefit because high oulfur content can be correlated with many of the problems associated with steam generating equipment (Babcock and wilcox 1972).

The principal benefit derived from coal cleaning, aside from sulfur reduction, is the reduction of ash content. Reduced ash content means reduced costs for shipping, storage, and handling because of the smaller quantity of coal required per unit of heating value (Babcock and Wilcox 1972 ).

Cleaning costs must be offset by the benefits obtained. Included in the cost of cleaning are plant operating costs, capital charges, the value of the coal discarded as refuse, and the cost of disposing of the refuse. Generally, the quantity of coal losi to refuse increases as the ash content is reduced.

One of the most significant factors in the overall fuel cost equation for a utility is the cost of transporting the fuel to the utility. This cost can easily equal or exceed the F.O.B. cost of the raw coal. Reductions in transportation costs allow significant potential for offsetting preparation costs. Although preparation costs are incurred by the producer, it is the consumer who will ultimately pay 
for preparation in the form of increased coal cost. If the increased coal cost is offset by reduced transportation costs, preparation is economically advantageous to both consumer and producer.

By balancing preparation costs against the consequent reduction in transportation costs, an optimum coal preparation scheme can be devised by the producer (Babcock and wilcox 1972). Commonly, an operator cannot recover the direct cost of upgrading his product but rather enjoys indirect economic benefits from coal preparation. Decreased mining costs and increased market opportunities are examples of the indirect economic benefits of coal preparation. It is primarily through indirect benefits that most operators profit from coal preparation efforts (Leonard and Mitchell 1968).

Although coal preparation encompasses a broad spectrum of processes applied to raw coal between mining and consumption the term is frequently used to describe coal beneficiation or upgrading, more specifically coal washing. This use has become common because some aspects of preparation are essential parts of use and, as such, are assumed. Whereas, the optional aspects of coal preparation have, in actual use, been largely lirited to coal washing.

\section{Essential Coal Preparation}

Preparation is a broad term that encompasses all processes applied to a coal between its extraction and its final use. There are many aspects of coal preparation, including comminution (size reduction by breaking, crushing, and grinding), classification by size (screening), upgrading or beneficiation (removal of noncalorific materials), transportation, storage, and the disposal of process wastes. Comminution, sizing, transportation, storage, and waste disposal are integral parts of any coal use and, thus, are termed essential preparation. The characteristics of western coal influence most aspects of its use and preparation including the basic operations of essential preparation.

Comminution. Comminution is a generic term used to describe breaking, crushing, and grinding operations used to achieve a controlled size reduction of raw coal. Mining is essentially a comminution process in which coal is broken from the seam and removed in pieces small enough to load.

Most coal burning equipment requires coal of a specific size range. coal is crushed at the preparation plant to meet the size required by the intended market. crushing is also the first step in most coal beneficiation or washing processes; it is used to help liberate the mineral impurities from the raw coal and generate a size consist compatible with the washing equipment at the plant (Tsai 1982). Generally, western coal is not washed, and crushing to a size compatible with washing equipment is not a common concern for this resource. The majority of western coal finds its use as steam coal, much of which is burned in pulverized coal-fired (pc) boilers. Coal specifications for pc boilers generally call for delivered coal prepared to sizes smaller than two inches (Babcock and wilcox 1972). 
pulverized coal-fired boilers generally require coal sized so that about 708 passes through a 200 -mesh $(74 \mu \mathrm{m})$ screen. Coal is shipped to the utility as two-inch top size. At the utility, it is crushed to minus $3 / 4$ or $1 / 2$ inch and fed to pulverizers, where it is reduced to minus-200 mesh. The pulverization is always done at the utility because handling minus 200-mesh coal is extre..ely difficult.

crushing to a top size at the mine and grinding to pulverized fuel are widely practiced on western coals. Western coal properties that are most significant with regard to comminution are grindability and moisture content. The high moisture levels typical of western coals make them more difficult to pulverize. This problem has been accommodated by drying the coal in the grinding mill with heated air, which also serves to transport the coal from the mill to the burner. Generally, designers of crushing and grinding equipment have been able to adapt present day comminution equipment to operate successfully on western coals. There do not appear to be any fundamental gaps in comminution theory as it applies to western coal; however, the high moisture content of western coal must be considered when designing pulverizing equipment (Gronhovd et al. 1982).

Dust generation in the crushing operations must be given special consideration for many western coals. Coal mining and processing in western areas can cause conflicts with scenic uses of surrounding lands. Total suspended particulates in the air are generally quite low and visibility is good in the western region; therefore, particulate emissions are easily noticed. Given the economic importance of tourism in the western region, care must be taken to limit particulate emissions.

sizing. Sizing is the separation of broken coal particles into arbitrary groups consisting of particles within restricted size limits. Coal particles are irregular in shape; therefore, the actual particle size is difficult to determine. Size is actually defined in terms of the size of a surface opening through which a particle will pass and the size of an opening that retains the particle (Leonard and Mitchell 1968). The sizing of coal results in separation into groups of particles sized below a given maximum and above a given minimum.

sizing is generally accomplished through the use of screens. Screens may operate either wet or dry; wet screens (where water sprays wash the fine particles through the screen openings) are commonly used for particles less than $3 / 8$ inch. Screens may be either stationary or activated; however, stationary screens are less efficient and see limited use.

There are four basic reasons for sizing coal. First, the separation of raw coal into various sizes is required by the markets. Second, separate sizes are required by various washing units. Third, specific gravity control medium is recovered from washing circuits. Fourth, coal fines produced during processing are recovered (Leonard and Mitchell 1968). Very little western coal is washed; thus, only the first reason for coal sizing is applicable to western coals. 
Most western coal is used by utilities and fired in pulverized coal (pc) burners. Western coal is generally crushed at the mine to a size, such as minus 1.5 or 2 inch, that is easily handled, transported, and stored. Most western coal is sold in sizes less than 2 inch. The high friability and weathering characteristics of western coal result in increased dustiness in screening and sizing operations. Dust control for these processes is an important consideration when sizing western coals.

Storage and Handling. Coal is stored at several places between the mine and its eventual end use. Coal is stored at the loading terminal at the mine. If the mine has an associated preparation plant, coal is commonly stored at the plant. Coal is stored at various transshipping terminals, and coal is stored at the location of the final user. The basic reason behind coal storage is to create a buffer that allows continuous operation of the various facilities regardless of fluctuations in the coal supply. The flow of coal from a mine may vary according to mining conditions, areas of changing coal quality, weather and equipment problems, and labor disputes. Utilities desire a steady flow of coal to their boilers. Interruption of the coal input can result in very expensive disruptions of generating capacity. Coal is stored in sufficient quantity to avoid disruption of service due to supply problems.

The quantity of coal that a utility stockpiles is strictly an economic decision made by weighing the cost of stockpiling the coal against the potential costs of shutting down the plant and purchasing electricity elsewhere. Most fluctuations in coal supply can be accommodated with a few days reserve. However, labor disputes can disrupt supplies of coal for long periods, and the storage of several weeks coal supply is not uncommon.

Shipment of coal by unit train requires sufficient storage and handling capacity at the loading facility to load an entire train in a minimal time. Preparation plants commonly work on schedules different from those of the mines that supply them. This makes it necessary to store feed coal for the plant.

Coal may be stored in exposed stockpiles or in bins or silos where it is fully or partially protected from the weather. The goal of any storage system is to minimize product degradation. The changes in coal caused by storage are loss of heating value through oxidation, changes in coking properties, reduction in average particle size by weathering or slacking, loss of product through windage, and most importantly, loss of product through spontaneous combustion (Babcock and Wilcox 1972). Several of the characteristics of western low-rank coal affect its storage. The high reactivity of western coals, the tendency of western coals to weather or slack, and the high moisture content of western coals, all contribute to potential storage problems.

The higher reactivity of western coals contributes to their tendency to oxidize more rapidly than bituminous coals. oxidation results in product degradation and possible spontaneous ignition of the coal. oxygen at the coal surface is a requirement for oxidative degradation. 
spontaneous ignition reguires that the heat of oxidation is not dissipated as fast as it is produced. Control of degradation by oxidation is achieved by thorough compaction of the coal stockpile to reduce oxygen availability to the coal.

The weathering properties of low-rank coals tend to increase product degradation through surface oxidation. As the old surface spalls off, the new surface is exposed to the elements. This problem also increases dustiness of the stockpiles and consequent product loss through windage. Product 108 s to weathering has been reduced by the application of drift fences (Babcock and Wilcox 1972) and surface treatment of storage piles with no. 6 fuel oil (Gronhovd et al. 1982).

spontaneous heating of storage piles is a function of many interrelated variables, one of which is the moisture content of the coal. Spontaneous heating of coal piles is not fully understood, but the basic mechanisms involved are sufficiently clear to allow low-rank coal to be stored successfully. Proper shaping and compaction of the coal storage piles has proven effective in preventing spontaneous combustion of stored coal.

Although the properties of western coal affect its handling and storage characteristics, these problems are not unique to western coal. Experience has demonstrated methods that work well for handling and storage, and precautions that should be taken when dealing with various coals. Storage of western coal should not present problems when established methods of compaction and pile shaping are adhered to; however, dust control must be given special consideration when storing western coals because of their weathering characteristics.

Disposal of Refuse from Coal preparation. When coal is upgraded, a product with lower mineral-matter content is generated, and a portion of the raw coal with a high concentration of mineral matter is removed. The handling and disposal of this mineral-matter-rich fraction is one of the problems that must be dealt with when devising a coal preparation scheme. Ultimately, the refuse removed from raw coal must be returned to the environment, and applicable environmental regulations must be adhered to.

Refuse from coal-cleaning plants can cause environmental problems through several mechanisms. Perhaps the most significant of these is acid leaching. Sulfur and oxygen compounds from the refuse can combine with water to form highly acidic liquids. In turn, these liquids can dissolve and mobilize toxic trace elements. Acid leaching can be controlled by neutralizing the waste before disposal or by the exclusion of water from the refuse disposal. This is accomplished by careful location of waste disposal sites out of the way of natural runoff and by compaction of the refuse to limit its permeability to water (Hutton and Gould 1982). Air pollution from entrained dust and various gases is also a consideration for preparation plant designers. Dust is controlled through the use of hoods and exhausters, which feed various types of mechanical separators, wet scrubbers, electrical precipitators, and filters that limit airborne emissions. 
Water used in the washing of coal becomes laden with suspended solids. Fine particles of coal and clays can remain in suspension for long periods and contribute to the pollution of surface water. Current washing plants are generally designed to recirculate wash water after clarification to minimize environmental concerns and reduce the quantity of water that is used.

Although the problems associated with the disposal of preparation refuse are manifold; they are, to a large degree, site specific. Available technologies are sufficient to allow most operators to meet current environmental regulations. Generally, a system of waste containment is devised so that interaction between the waste and the environment is minimized. As more stringent environmental regulations come into play, the disposal of preparation plant wastes will become a greater and greater part of the cost of coal preparation.

Western subbituminous coal has historically seen very limited beneficiation. Only a small fraction of subbituminous coal is cleaned; in fact, there is only one coal preparation plant that washes this coal in the West. Waste disposal as it relates to western coal beneficiation is, therefore, not a serious problem. However, should the future see an increase in western coal cleaning, the properties of these coals may result in an alkaline leachant as opposed to the acid leachant of eastern coals. Methods of containment that are applicable to eastern coal refuse should still be applicable even though the contained material will possess different properties.

\section{Coal Beneficiation}

The term beneficiation is used to describe nonessential coal preparation technologies, which are used to upgrade characteristics of raw coal and increase its value. Coal beneficiation processes reduce the impurities associated with the raw coal, thus, generating a purer, higher value product. In recent years, the use of beneficiation technologies based upon mineral-matter reduction has increased steadily. Most of this increase has been applied to eastern coal to reduce precombustion sulfur levels. Considerable research has been directed toward improving sulfur reduction technologies, and a wide range of options have been developed toward that end.

Coal beneficiation technologies can be divided into three general categories: (1) physical separations, (2) chemical separations, and (3) coal drying (schobert 1987). Each of these categories deals with a different group of impurities, but all are aimed at increasing the value of the product by reducing the amount of extraneous material found in the raw coal.

Physical separations. Physical separations are used to reduce the mineral-matter content of coal. These processes are based upon differences in the physical properties of pure coal and its associated mineral matter. The most common physical separations take advantage of the different specific gravities of coal and the coal minerals. Other physical separations use surface property differences, magnetic differences, and electrostatic differences. Physical separation of mineral matter is the only category of beneficiation currently practiced on a substantial commercial scale (Schobert 1987). 
Gravity separations. specific gravity is density of a substance compared with the density of water. Methods employed to clean coal that are based upon the difference in specific gravities of the coal and the mineral matter associated with it are commonly referred to as gravity separations. There are several different devices that operate on this principle allowing gravity separations to be applied to a broad range of coals. Gravity separation is the most commonly used method of coal cleaning in the United States.

Washability studies are used to estimate how well a coal will respond to cleaning by gravity separation. The study is made by testing a coal sample at preselected, carefully controlled specific gravities and is commonly referred to as float-sink testing. Generally, the specific gravity fractions obtained in the test are dried, weighed, and analyzed for ash content; although, other analyses (e.g., sulfur content) may also be performed (Leonard and Mitchell 1968). Data from these tests are used to determine preparation methods and equipment for a given coal.

Coal typically has a specific gravity that ranges from 1.12 to 1.35 , whereas common coal impurities have specific gravities that range from 1.35 to 5.2 (Babcock and Wilcox 1972). The greater the difference in specific gravities, the more easily the components can be separated. Gravity separations deal with mineral matter that is physically mixed with the coal but not chemically incorporated into it.

Gravity cleaning methods can be either wet or dry, but the most commonly employed methods are wet concentrations. In the wet processes, water is the separating medium; dry processes generally use air as the separating medium. Dry processes are also generally limited to coal sizes less than 0.75 inch. Gravity cleaning methods include densemedium separation, hydraulic separation or jigs, concentrating tables, dense medium cyclones, and hydrocyclones. Each process has certain limitations with regard to optimal particle size, space requirements, water use, and sharpness of separation. Generally, the cleaner the product, the more coal is rejected with the mineral matter.

Gravity coal cleaning technologies have been applied extensively and with considerable success in the beneficiation of eastern coal where reducing mineral-matter and sulfur content are important factors affecting the marketability of the coal. Gravity cleaning has seen only minimal application with western subbituminous coal, mainly because of the characteristics of this resource.

Western low-rank coals are typically surface-mined coals that have a low extraneous mineral-matter content, low sulfur content, and high moisture content. Typically, western coals are relatively clean in their raw state; therefore, the benefits to be derived from physical cleaning methods are minimal. The use of water in many of the physical cleaning processes can add moisture to the coal, offsetting some of the benefits derived from mineral-matter reduction. The value added rarely exceeds the processing costs (Gronhovd et al. 1982); therefore, western low-rank coals are rarely physically cleaned. 
only one western coal mine currertly washes subbituminous coal. The coal that is cleaned at this plant is not typical of the western subbituminous coal as it is characterized in this report. The Washington Irrigation and Development Company at Centralia, Washington, strips coal from a folded and falited seam. The operation generates a raw coal with an unusually high mineral-matter content, and it is washed prior to its use at an adjacent steam-electric facility (Keystone 1987). Coal from an underground mine at Hanna, Wyoming, was washed in a dense medium plant. The mine and preparation plant were operated by Energy Development Company, which also operated a ourface mine at Hanna. The cleaned coal from the underground mine was mixed with the surface-mined coal upgrading the quality of the combined product. The primary reason for cleaning this coal was to prevent boiler problems created mainly by ash fusion (Jackson 1978).

As with all coal cleaning, the decision to wash these two subbituminous coals was based upon site-specific coal characteristics and the requirements of the markets. It is also of some consequence that both western coal-cleaning plants are owned by subsidiaries of the utilities that ultimately consume the products. The Hanna plant no longer operates due to a change in market conditions.

As energy costs rise and environmental standards tighten, the economics of physically upgrading low-rank coals will tend to improve. Coals that can benefit from physical cleaning may be mined in the future, and coal conversion processes that require selective or general reduction of mineral matter may become significant forces in the western coal market. The limited data that exist on the washability of western low-rank coal suggest that many of these coals will respond well to gravimetric cleaning (Deurbrouck 1971; Jackson 1978). However, Glass (keystone 1987) reports that because most of the sulfur is in the organic form, even a complete removal of pyritic oulfur will reduce total sulfur by a maximum of 308 .

If future markets for western coal require a cleaner product, preparation plant designers will be faced with several potential obstacles. First, pertinent experience in cleaning western coal is lacking, and a consequent shortage of data on which to base decisions as to what cleaning methods are best will have a significant effect. second, the shortage of water in many western areas and its relatively high value may change the desirability of some beneficiation processes. Finally, the high moisture content of the raw coal may necessitate thermal drying of the cleaned coal product to meet market specifications.

Separations Using Surface Properties. Although separations based upon specific gravity are the most widely used coal cleaning methods in the United states, these processes do have their limitations. As the particle size to be washed decreases, gravity methods of separation become less and less efficient. Other forces acting upon the particle increase in significance as particle size decreases. Although the force of gravity still acts upon small particles, the rate at which the particles settle may be very slow. As particle size decreases, the surface area-to-volume ratio of the particle increases. This makes processes that deal with surface properties more desirable as a means of 
separating the fine coal from its associated contaminants. Froth flotation and oil agglomeration are examples of coal cleaning technologies that take advantage of the different surface properties of the coal and mineral matter.

Flotation cleaning relies upon the selective adhesion of air and water to the surface of different solids. Solids to which water will adhere readily are termed hydrophilic, whereas those to which water does not adhere readily are termed hydrophobic. Air tends to adhere more strongly to surfaces that are hydrophobic. Coal can be separated from some coal minerals by passing finely disseminated stream of air through a slurry of coal in water. The particles to which air adheres more strongly, typically the coal, float to the surface, whereas the particles to which water adheres sink (Leonard and Mitchell 1968). The coal and air forms a froth (thus, the name), which can be skimmed from the surface.

Small quantities of selected reagents are commonly used to enhance the flotation separation. Frothing reagents are used to help to increase froth stability by modifying the surface tension of water. collector reagents promote contact between coal particles and air bubbles by forming a thin coating over the coal particle, thus, rendering the particle more water repellent. Some frothers have both frothing and collecting properties. Modifying reagents are used for a variety of purposes such as inhibiting flotation of unwanted material or regulating the $\mathrm{pH}$ of the flotation mixture. Proper selection of reagents is of prime importance to the success of flotation coal cleaning. For coal cleaning, a combination frother/collector is generally the only reagent needed; however, the appropriate reagent or combination of reagents depends upon the properties of the coal to be cleaned.

Flotation cleaning of fine coal has several advantages, the first of which is an ability to clean extremely fine coal. optimum particle size for froth flotation is between 48 and $150 \mathrm{mesh}$, but its application has been successfully extended to particle sizes less than 325 mesh (Leonard and Mitchell 1968). Relatively low capital and space requirements, relatively high throughput with a wide range of operating conditions, and adaptability to a wide range of feeds through proper reagent selection make froth flotation a primary choice for the cleaning of fine coal (Mishra and Klimpel 1987).

Preferential oil wetting of hydrophobic particles in an aqueous suspension is the basis of coal cleaning by oil agglomeration. This selective wetting allows coal particles to become coated with a thin film of oil. Agitation of the suspension causes the oil-coated particles to agglomerate, whereas the generally hydrophilic oxide minerals remain in suspension as fine particles. The larger agglomerates are then separated from the suspension and recovered as cleaned coal (Mishra and Klimpel 1987).

Oil agglomeration may find its greatest application in removing coal fines from coal-water slurries and plant discharges. Oil agglomeration not only recovers the coal from these slurries but also reduces the ash and moisture content of the recovered coal. Moisture is displaced by 
the adsorption of oil at the particle surface. The surface area of the agglomerate is considerably smaller than that of the feed, which results in less moisture entrapped in the product (Tsai 1982).

oil agglomeration can selectively recover nearly 1008 of combustibles from a wide range of fine coal slurries or plant waste streams while rejecting inorganic impurities and moisture. oil agglomeration is applicable to a wide range of coala with high recoveries of combustibles; however, ash rejection generally decreases with decreasing coal rank (Mishra and Klimpel 1987). A major advantage of the process is its ability to recover, clean, and dewater minus-200mesh coal.

Like froth flotation, oil agglomeration is a rather sophisticated process compared with the more commonly applied coal preparation methods. The most significant factor regarding the economics of its application is the cost of the agglomerating oil; however, this cost must be weighed against the value of the recovered coal and the cost of disposal of unrecovered coal. The surface properties of typical western coals are considerably different from those of typical eastern coals. Western subbituminous coals tend to be less hydrophobic than eastern bituminous coals. Proper reagent selection can enhance the hydrophobic property of the coal surface without decreasing the hydrophilic properties of the mineral matter. The finely dispersed nature of the mineral matter in low-rank coals may make fine coal cleaning of particular significance to the western coals (Gronhovd et al. 1982). There are very limited data available on the application to western coals of the various fine-coal-cleaning methods now being developed and applied to eastern coals. Considering the variety of processes available, and the adaptability of these processes through selection of appropriate reagents and conditions (Mishra and Klimpel 1987), finecoal-cleaning methods can probably be successfully adapted to western coals.

Magnetic separations. Coal can be separated from some mineral impurities by taking advantage of the different magnetic properties of coal and coal mineral matter. Coal is basically diamagnetic (repelled by a magnetic field), whereas most coal minerals are generally paramagnetic (attracted by a magnetic field). The magnetic properties of some coal minerals, particularly pyrites, can be enhanced by chemical treatment allowing for separation in magnetic fields of lower intensity than those required for untreated coal (Tsai 1982).

Magnetic separation technologies may provide additional options for preparation plant designers in the future. The processes may find particular application to deep cleaning some coals in conjunction with other physical cleaning methods. The magnetic processes seem to offer greater reduction of pyritic sulfur with higher coal recovery when compared with two-stage froth flotation. As with the other physical coal cleaning technologies, magnetic separations are used to reduce the mineral-matter content of the raw coal. Because reduction of mineral matter is of minimal value in upgrading typical western coals, little data exist on the application of magnetic cleaning processes to western coal. 
Chemical coal cleaning. The coal beneficiation processes discussed thus far all rely upon differences between the physical properties of pure coal and those of common coal impurities. Another broad category of coal beneficiation finds its basis in the chemical behavior of pure coal and coal minerals. Some impurities are physically mixed with the pure coal; however, others are chemically bound to the coal structure and can only be removed through the breaking of chemical bonds. There are also extremely fine impurities that, although not chemically bonded to the coal, are locked within the coal pore, sructure; thus, they are inaccessible to physical upgrading methods.

The main objective of chemical coal cleaning technologies has been the development of extremely clean coals. To offset the higher costs of the more rigorous treatments, compared with physical cleaning methods, the processes must generate a coal sufficiently clean to burn without subsequent flue gas desulfurization (International Energy Agency 1985). The required level of coal desulfurization is determined by $\mathrm{SO}_{2}$ emission regulations at a given site.

Although specific reagents and conditions vary among the processes, generally, all treat the coal with a chemical reagent for a time sufficient for reaction with the impurities. Treatment is commonly at elevated temperature and pressure. The reaction product containing the impurities is then separated from the coal, and the reagent is regenerated leaving the impurities in a disposable form.

Chemical coal cleaning methods have been developed that remove organic as well as pyritic sulfur with nearly complete removal of pyritic sulfur being attainable. Total sulfur removal rates of nearly 908 are obtained by some processes (Hutton and Gould 1982). Chemically cleaned coals may find a market as fuel for industrial boilers where flue-gas desulfurization systems may be impractical as a means of meeting emissions restrictions. Alternatively, if the economics are right, new power plants may be designed to burn very clean coal without the use of scrubbers.

The major advantage of chemical coal cleaning is the ability to remove nearly all of the pyritic sulfur from the raw coal with a nearly complete recovery of the pure coal. Some processes have the added advantage of removing organic sulfur. These processes will probably be most applicable to eastern bituminous coals, because they help plants that burn these coals meet $\mathrm{SO}_{2}$ emissions standards (Tsai 1982).

When compared with the physical methods commonly employed in coal beneficiation, chemical processes have several inherent disadvantages. Physical processes use relatively simple mechanical equipment that is easy to build, operate, and maintain. Physical processes operate at or near ambient conditions, and a large base of operating experience exists that commonly can provide solutions to particular coal cleaning problems.

In contrast, chemical beneficiation systems are complex by coal preparation standards. Most operate at elevated temperature and/or pressure, which can add to initial plant cost and increase operating costs (Schobert 1987). Reagent consumption and cost will be greater for 
chemical coal cleaning as will costs for electricity to operate reactors, slurry pumps, and dewatering systems (Hutton and Gould 1982). chemically cleaned coal is generally physically cleaned prior to chemical beneficiation, and problems associated with both cleaning methods must be dealt with.

The problems associated with refuse disposal, water availability, equipment maintenance, dust emissions, and storage and handling of the raw and cleaned coal will probably be compounded for chemical cleaning plants. Many of the solutions to these problems will be similar to those employed by physical cleaning plants, but some unique problems associated with the particular reagents used may require new solutions.

The environmental concerns that chemical plant operators must deal with will have to be assessed with regard to chemical coal cleaning plants. Operators must ensure that emissions of process gases, particulates, and effluents all meet applicable standards. Potentially toxic, corrosive, or caustic chemicals must be handled safely in an environment where mechanical dangers and dust problems have been the major concerns in the past.

To offset the relatively high cost of chemical coal cleaning, the value added to the product will have to be significant. At first glance, it seems unlikely that coal can attain a value high enough to offset the cost of chemical cleaning. However, the high cost of fluegas scrubbing (estimated at $\$ 30.00 /$ ton of coal, Hutton and Gould 1982) and savings in transportation costs and boiler operating expenses allow for a considerable increase in fuel costs, provided that a coal clean enough to burn without flue-gas cleaning can be produced.

As a general rule, all the chemical coal cleaning processes have focused mainly on eastern bituminous coal and on oulfur reduction. Western low-sulfur coals will benefit little from the processes that deal only with pyritic sulfur. A few processes have been tested on western coals. Although substantial sulfur reductions were achieved, the amount of relief that chemical cleaning will provide to the flue-gas desulfurization equipment is relatively small (Gronhovd et al. 1982).

Chemical cleaning of western coals under current market conditions is obviously not practical. Unless legislation requiring very low sulfur levels in utility boiler fuel is enacted, chemical cleaning of western steam coal for sulfur reduction may never be practical. Future coal conversion processes may employ chemical cleaning methods, but it seems likely that the cleaning will be part of the process and not a form of preparation practiced by coal producers.

Chemical comminution has been proposed as an alternative to mechanical crushing and grinding of coal. The process involves penetration of the naturally occurring interstices, faults, pores, and other discontinuities in coal by certain low molecular weight compounds that disrupt the internal bonding forces and cause the coal to fragment (Tsai 1982). Observations suggest that the breakage occurs along internal boundaries previously weakened by the infiltration of mineral constituents. Thus, the coal is selectively fractured in a manner compatible with mineral separation. 
The wide variability of coal characteristica and mineral distribution suggests that response to chemical comminution will depend upon properties of the particular coals to which it is applied. Because western coals are generally not cleaned prior to sale, the process will probably be more applicable to eastern bituminous coals.

Sodium content is the most important aingle factor affecting ash fouling characteristics for a given coal (Babcock and wilcox 1972). Ash fouling can be of considerable significance, especially when boilers are operated at high loads, and sodium reduction can markedly upgrade the quality of high-sodium coals. Sodium in coal is ionically bonded to oxygen-containing functional groups that are evenly distributed throughout the coal mass; therefore, physical separation methods commonly employed to reduce mineral-matter content are not effective in removing sodium from coal.

Ion exchange techniques are applicable to sodium reduction in coals. Ion exchange allows the replacement sodium in coal by ions of greater ionic weight, higher electronegativity, or higher ionic concentration. sodium can be replaced by potassium, calcium, iron, magnesium, or hydrogen ions depending on process conditions.

Sodium reduction through ion exchange has been investigated at the Grand Forks Energy Technology Center (GFETC) at a scale of $100 \mathrm{lb} / \mathrm{hr}$ coal feed. A continuous countercurrent reactor was used to investigate the effects of process variables such as particle size, solids and liquid residence times, various cations, and cation concentrations on the level of sodium reduction. Sodium reduction was most effective with small particle sizes and high cation concentrations; however, as with most coal cleaning processes, the conditions that produce the cleanest coal also lose the most amount of product to the waste stream and require the most cleanup (Gronhovd et al. 1982).

Western lignites and some western subbituminous coals are relatively high in sodium. Ion exchange sodium reduction can generate a more saleable product. Preliminary economic evaluations of ion exchange cleaning of North Dakota lignites have been favorable (University of North Dakota under contract to GFETC). The costs of boiler downtime resulting from fouling will need evaluation because the value of reduced downtime must offset the cost of preparing a nonfouling coal.

Potential problems with disposal of the concentrated sodium brine may affect the applicability of ion exchange coal cleaning. The cationdonating reagent expense must be considered, and environmental concerns when dealing with large quantities of chemicals must be carefully evaluated. Ion exchange processes take place in a water solution so a liquid-solid separation must be made. Adding water to high-moisture coal can decrease its value if subsequent dewatering steps are not completely effective.

Moisture Reduction. Although ash-forming minerals and sulfur are the most consequential impurities in eastern bituminous coals, the most significant impurity in western low-rank coals is moisture. Moisture does not contribute to the heating value of coals, but it does add to 
its weight. Therefore, its presence is detrimental and, like ash and sulfur, reduces coal quality. Not only does moisture not contribute to heating value, but also the energy required to vaporize the moisture and heat the vapor to exit gas temperature must be supplied by the calorific constituents of the coal. Thus, the usable heat content of the fuel is reduced.

In addition to reducing the coal heating value, excess moisture contributes to a number of other handling and combustion problems. Frozen coal can be a major problem during winter months causing difficulties in unloading rail cars; cars may return to the mine with up to twenty tons of frozen coal stuck to the car bodies, which is a tremendous waste (Keystone 1987). Frozen or moist coal can plug chutes, bins, and downspouts causing operational difficulties.

Excess moisture limits the capacity of pulverizers and can increase the number of pulverizers required for a given installation. High moisture levels in the fuel result in high moisture levels in the flue gas. This requires higher stack gas temperatures to prevent formation of corrosive sulfuric acid in the air heaters. Increased stack gas temperatures reduce overall thermal efficiency and result in higher operating costs. More power may be required by the forced-draft fan to provide sufficient heated air to dry moist coal in the pulverizers.

Although the problems associated with the combustion of highmoisture coal are significant, the proper design of combustion and handling equipment can effectively solve these. The greatest detriment to the use of high-moisture coal, transportation cost, cannot be mitigated so easily. Fuel transportation costs are a major factor in the overall fuel and operating expenses for utilities that burn coal. Railroad transportation cost can easily exceed the mine-mouth cost of raw western coal (Gronhovd et al. 1982), and transportation alternatives currently do not exist.

The cost of coal transportation is difficult to generalize. Transportation rates are negotiated and contracted on an individual basis, with consideration given to yearly volume, transport distance, ownership of rail cars, and a host of other variables. However, published data on rail transit rates in 1988 show that 1.5 to 2 cents per ton per mile is typical.

Mechanical Dewatering. Moisture reduction in coal is accomplished by either mechanical dewatering or thermal drying. Mechanical dewatering is essentially a liquid-solid phase separation and employs methods common to this type of separation. The difficulty of separating liquids from solids is inversely proportional to the solids particle size. Thus, the method of separation is determined, to a large extent, by the particle-size range of the coal to be dewatered.

Generally, coal sizes larger than 1.5 inches are dewatered on shaker screens. High-3peed vibrators are used for dawatering of 1.5- to 0.25inch coal. Coal from 0.25 inch to 28 mesh is typically dewatered by centrifugation, whereas smaller sizes are commonly vacuum filtered (Leonard and Mitchell 1968). In practice, there is significant 
overlapping of the various dewatering methods depending upon product moisture requirements, available equipment, and relative concentrations of coal fines.

Mechanical dewatering is used to separate the coal from the water in coal-water slurries and to remove the water left on the coal by wet beneficiation processes. Removal of water remaining after wet beneficiation is of very little significance to western coals because almost none are cleaned by wet processes. Currently, Black Mesa coal is the only western coal transported by slurry pipeline, and conventional dewatering techniques have been applied successfully to this slurry. How well western coals will respond to mechanical dewatering techniques is not fully known. It is likely that methods applicable to the larger sizes of eastern coal will work on large-sized western coals, but how well western coal fines will respond to mechanical dewatering is not known beyond the experience gained at Black Mesa.

Future developments in the use of western coal may require increased use of mechanical dewatering as more coal is washed or transported by slurry pipeline. There is little movement in this direction at this time; planned coal slurry pipelines have not materialized; and no new subbituminous coal-cleaning facilities are coming on-line in the near future. Therefore, the mechanical dewatering of western coals probably requires no further development at this time. Mechanical dewatering may become very significant to western coal if slurry transportation is employed in the future.

Thermal Drying. Thermal drying of coal is used to:

- Save on coal transportation costs

- Increase heating value and selling price

- Prevent handling problems caused by freezing

- Improve the quality of coal used for coking, briquetting, and chemical production

- Improve operating efficiency and reduce maintenance costs of boilers

- Increase coke oven capacity

- Increase pulverizer capacity

- Decrease boiler fuel throughput requirements

Although thermal drying has the ability to significantly improve overall product quality, there are some problems associated with the coal that is produced by current methods. Dried coal exhibits an increased susceptibility to spontaneous ignition and is more friable than raw coal. This increases size degradation and dust formation. The dried coal can also reabsorb moisture if the surface is not treated. When compared with dryers operating on eastern bituminous coal, the material capacity of thermal dryers is substantially reduced when drying western coal. The water evaporation rate tends to limit the throughput of thermal dryers; thus, dried product output is roughly inversely proportional to feed coal moisture.

There are three basic types of moisture in coal: free, physically bound, and chemically bound. Free moisture exhibits a normal vapor pressure similar to that of free standing water and is easily removed. 
Purely mechanical dewatering methods are capable of removing free water from coal. Free water can be found wetting the coal surface and in the very large pores and interstitial spaces of the coal mass.

Physically bound moisture is also commonly referred to by other terms, among which are inherent moisture, combined moisture, and capillary moisture. Physically bound moisture is more difficult to remove because it is held more tightly in the smaller pores and capillaries of the coal. Physically bound moisture has a lower vapor pressure and specific heat than free moisture.

Chemically bound moisture is the portion of the moisture that is chemically bonded to the coal structure. Chemically bound moisture is commonly identified as either multilayer or monolayer type. Monolayer moisture is bonded to oxygen-containing functional groups in the coal complex, whereas multilayer moisture is weakly hydrogen bonded on top of the monolayer moisture. Chemically bound moisture also includes water of hydration associated with carboxylate-group cations and minerals such as calcium sulfate.

Decomposition moisture is formed by the chemical decomposition of organic molecules in the coal structure. As such, it is not really a form of moisture held by the coal but rather a product generated as the coal undergoes certain chemical reactions. The oxidative reactions that form decomposition moisture can generally be regarded as combustion. These reactions can take place at temperatures below $100^{\circ} \mathrm{C}\left(212^{\circ} \mathrm{F}\right)$ and can contribute to the measured coal moisture when standard ASTM methods involving sample drying and determination of moisture by weight difference are used.

Because of the various types of moisture in coal, the drying rate is not constant throughout the drying period. Luckie and Draeger (1976) presentud a conceptual description of a typical coal drying curve (Figure 7). The first portion of the drying curve (1-2) represents the initial unsteady system response as it seeks an equilibrium condition. The next portion of the drying curve $(2-3)$ is the constant drying rate portion, so named because this portion of the curve is linear. For this portion of the curve the slope (rate of drying) is constant. The material temperature also remains constant during this phase of drying. During the constant rate portion of the drying cycle, the drying rate is controlled by external factors (i.e., the contained moisture is exhibiting the properties of unbound moisture). During this period, the drying process is independent of the type of material. Any coal of a given size, indeed any solid of that size, will exhibit the same drying rate when exposed to the same drying conditions.

The last portion of the drying curve (3-4) is the falling-rate portion, so named because the slope (drying rate) of this curvilinear portion is decreasing. As the drying rate decreases, the material temperature increases, and drying rate is controlled by internal factors. The moisture contained in the coal behaves as bound moisture during the faliing-rate portion of the drying cycle. Particle size, temperature, and residence time are very important in determining the drying rate (i.e., the drying rate is dependent on coal properties). 


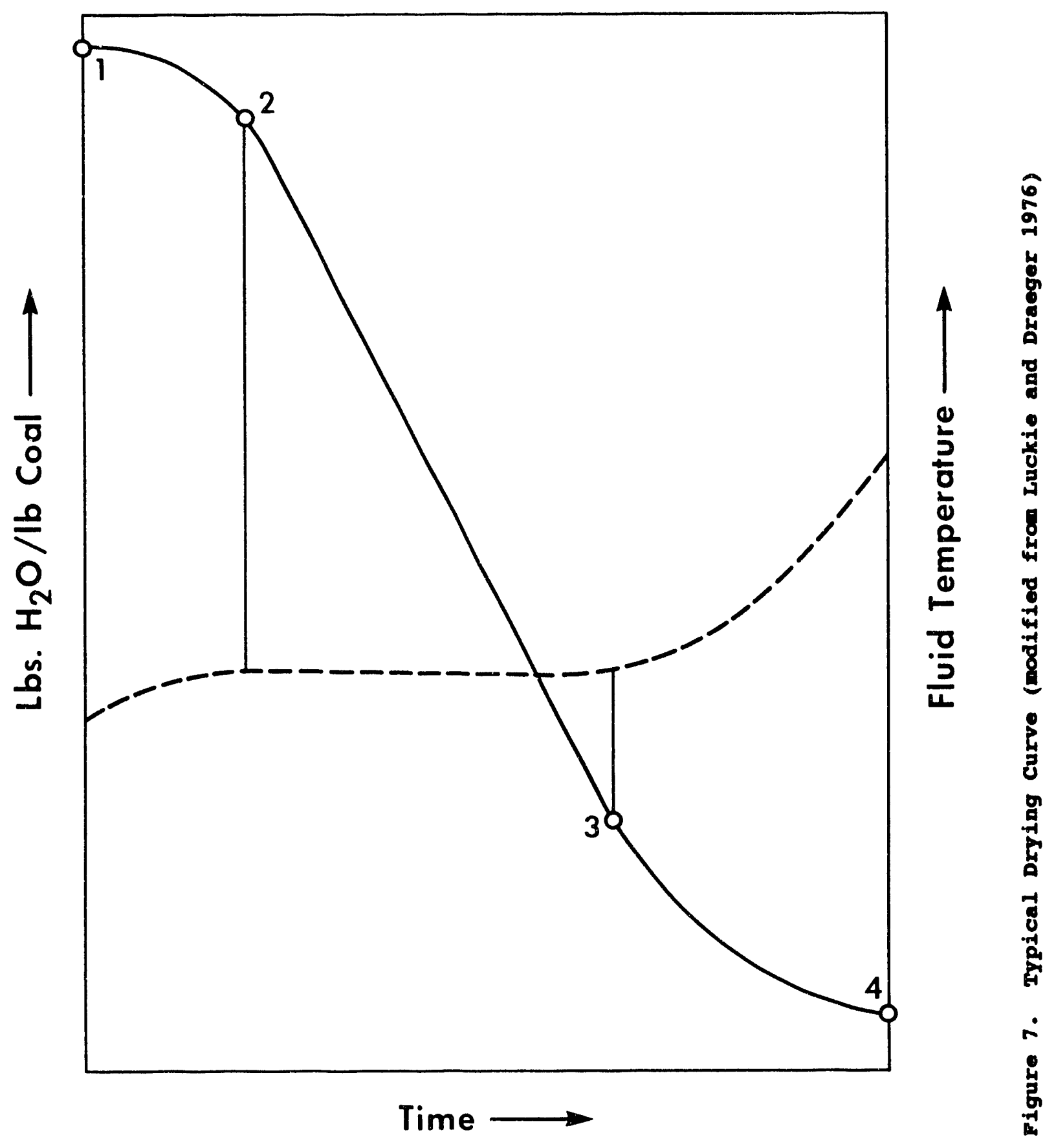


Although it may not be a definite point, the transition between constant- and falling-rate periods (point 3 ) is called the measured critical moisture.

During the constant-rate period, either the mass transfer or the heat transfer rate between the surface of the solid and the bulk gas phase controls the drying rate. That is, the ability of the drying medium to transfer heat to the coal or its ability to accept moisture from the coal controls the drying rate. Both of these factors are dependent upon the temperature and relative humidity of the drying media and independent of the properties of the material being dried.

As the coal moisture content decreases, the constant-rate period ends at the critical point (point 3 in Figure 7 ), and during further drying, the rate decreases. During this falling-rate period, the diffusion in the solid controls the overall drying rate. Throughout the constant-rate drying period, the entire particle ourface remains wetted, whereas only a part of the surface is wetted during the falling-rate portion. Heat added to coal surface water during the constant-rate portion of the drying cycle is equal to heat carried away by evaporation of this water, and the coal temperature approaches the wet bulb temperature of the drying media (Leonard and Mitchell 1968).

If the drying process is an independent operation, it is critical to treat dried coal to minimize or prevent moisture reabsorption and autogenous heating. In addition, dried coal is more friable and, thus, dustier than raw coal. In order to minimize these problems, it is common to spray oil on the coal after cooling, as it leaves the dryer. The use of 1.5 to 2 gallons of No. 6 oil per ton of coal has been effective in minimizing these problems (Bauer 1980); however, the addition of oil to the dried coal increases operating costs.

Some of the cost of oil treating can be recovered because the heating value of the coal is increased by the addition of oil. However, the net effect is one of selling oil at the price of coal, a prospect that is not economically attractive. The additional costs associated with procuring, handling and storing the oil, as well as the capital costs for the equipment needed for the oil treatment must also be considered. Clearly, a drying process that generates a stable saleable product without subsequent oil treatment is desirable.

Existing Thermal Drying Processes. Dry coal performs better than wet coal for many applications. The problems associated with the combustion of wet coal have been enumerated in preceding sections of this report. Rhodes (1949) reports that during world war II, the complete drying of the coal in Germany, greatly improved pyrolysis in Lurgi-spulgas ovens and the use of dry coal in France increased the capacity of coking ovens. The many advantages derived from the use of dried coal resulted in a trend of increasing tonnages of dry coal being sold in the United States during the $1950 \mathrm{~s}$ and most of the 1960s. Many drying processes were developed and commercialized. Processes aimed at drying and stabilizing western coal were investigated (Rice and Johnston 1951). However, changing coal market conditions and stringent emission standards were reversing the trend toward increased use of dried coal by the end of the $1960 \mathrm{~s}$. 
Industrial coal dryers generally heat the coal through convective heat transfer. Hot gases, typically combustion producta, directly contact the coal in the dryer as the coal is continually transported through. The gas heats the coal to vaporize the water, which is then removed with the exit gas stream in the vapor phase. This type of drying is generally known as direct-contact, convective drying. The different types of dryers operating on this principle can be classified as six basic types: fluidized bed, entrained flow (suspension or flash), multilouvre, vertical tray or cascade, continuous carrier, or drum type (Leonard and Mitchell 1968). Industrial coal dryers are essentially all of the continuous-carrier, direct-contact type, in which the coal is heated by convective heat transfer from a hot gas, typically a product of combustion. The gas heats the wet coal, as it is fed continuously to the dryer and vaporizes the moisture, which is then carried from the dryer with the exit gas.

In fluidized-bed dryers, the drying medium (hot gases) is forced through a restriction plate designed to evenly distribute the gas flow across the entire plate area. Wet coal is introduced to the dryer above the restriction where it is suspended (fluidized) by the gas stream. The suspended particles mix very thoroughly with the hot gases. The turbulent environment provides for very high heat and mass transfer rates with a corresponding high drying capacity. The coarse fraction of the dried coal is generally removed through an air-lock conveyor; the fines exit with the gas stream and are then collected in a dry dust collector, commonly to be recombined with the coarse fraction.

While the basic principle of fluidized-bed drying is simple, designing a drier system that will operate satisfactorily is far from easy. The system must reduce moisture to the desired level without burning or damaging the product. The system must be capable of coping with variations in feed rate and feed composition and must operate with a high degree of automation. The dryer also needs to be safe from explosion and fire hazards. The outlet gas nust be sufficiently clean to meet applicable emissions standards.

Well known examples of fluidized-bed coal dryers include the McNally Flowdryer, the Dorr-oliver Fluosolids dryer, the Link-Belt FluidF'lowdryer, and the Heyl and Patterson fluidized-bed dryer. These dryers are discussed in Coal preparation (1968), which contains more detailed descriptions and operating characteristics provided by the dryer manufacturers.

Typically, the fluidized-bed dryers use a stoker or pulverized coalfired air heater to heat and reduce the oxygen content of the fluidizing gas before it enters the drying zone. Some dryers recirculate a portion of the exit gas to further reduce the oxygen content in the drying gas. The pressure drop across the gas distributor (constriction plate) must be large with respect to the pressure drop across the bed. This will ensure even distribution of the drying gases. Feed coal distribution is controlled by a feeder-spreader device such as a roll feeder, multiplescrew feeder, or grate-type feeder. Coal feed top sizes are typically $3 / 8$ inch, 8 mesh, or 6 mesh. 
The fluidized-bed dryers are potentially hazardous when air or mixtures of air and gas are used as the drying media. Careful control of the drying-gas oxygen content and coal bed temperature are required to limit the potential of fire or explosion. Fluidized-bed drying systems typically incorporate sprinkler systems, blowout doors, and automatic fail-safe shutdown devices (Schreckengost 1963).

The water content of the dried coal is commonly held at 58 to 108 , or 0.58 to 1.08 surface moisture; this decreases hazard potential and avoids excessive dust formation. After nearly all of the surface water has been removed, bed temperature can be correlated with coal moisture and used as a control parameter. After the surface moisture is removed, bed temperature beging to increase and is controlled below the coal autoignition temperature to avoid hazardous conditions.

Particulate emissions from fluidized-bed dryers are controlled using a combination of cyclones, electrostatic precipitators, and wet scrubbers. The separation efficiency of cyclones falls rapidly when particle sizes are less than $10 \mu \mathrm{m}$, and cyclones are almost totally ineffective for separating particles smaller than $5 \mu \mathrm{m}$. Cyclones mainly reduce dust loading in the gas stream to the secondary separation device, which improves its efficiency.

Wet scrubbers use surface moisture to cause agglomeration of the fine particles making separation less difficult. Cyclones operated at the dew point of the gas stream or combined with high-energy water spraying can be nearly as effective as wet scrubbers. Electrostatic piecipitators, although used successfully in some operations, must be kept free of condensation, are susceptible to malfunctions, and require frequent maintenance and shutdown of the system.

One commercial dryer installation operating on western coal is a McNally Flowdryer system installed by AMAX Coal Company at its Belle Ayr mine near Gillette, Wyoming. The unit was designed to produce about one miliion tons per year of coal dried to about 108 moisture content. The dried coal product from this dryer has a heating value from 10,500 to $10,800 \mathrm{Btu} / \mathrm{lb}$ and, as of mid 1990, had been sold to some electric utilities (Glass 1990). Amax Coal Company announced that it is considering building up to five more drying units adjacent to its mines in Campbell county, Wyoming.

Suspension or entrained-flow dryers such as the C-E Raymond flash dryer use entrained fluidized beds to dry particles in a hot-gas stream with a residence time of one second or less. The wet coal is continuously introduced into a column of high-temperature gases; moisture removal is practically instantaneous (thus, the name flash dryer). High temperatures and a high degree of turbulence account for the rapid drying rate. The low residence time allows flash dryers to have a high capacity while maintaining a relatively small inventory of coal in the dryer. Thus, even the largest dryers have only about three hundred pounds of coal in the system at any given moment (Leonard and Mitchell 1968). The low coal inventory makes flash dryers somewhat less hazardous than slow fluidized-bed dryers. 
Heated air is used as the drying medium. Hot air is typically provided by a spreader stoker furnace; however, a pulverized coal-fired furnace is sometimes used. Coal is fed to the unit by a screw feeder when minus 3/8-inch coal. The unit can also be used to dry filter cake; although, premixing of the cake with some dried coal is required to facilitate dispersion in the gas stream. The gas stream leaves the dryer carrying the dried coal with it. The gas enters a primary collector, which is a large, high-velocity, high-efficiency cyclone. The dry coal is separated from the hot gas by centrifugal force and removed from the cyclone through an airlock seal. When drying filter cake, a portion of the dried coal is returned to the feed mixer to condition the feed coal. A secondary collector, such as a wet scrubber, can be used to further clean the gas and to collect the ultrafine material.

The flash drier is controlled by setting the outlet gas temperature to give the desired coal surface moisture. Inlet gas temperature is controlled by a tempering-air and shut-off damper in the hot-gas duct between the furnace and drying column. system control is very responsive because the coal inventory in the dryer is small. The high gas velocity used in the drying tube requires a difficult gas-coal separation to remove fine particulates from the effluent gas. In addition, the high gas velocity and turbulence can result in particlesize degradation as low-rank coals are dried. This size degradation will further increase the difficulty of the gas-solids separation and may result in the generation of excess dust at the expense of saleable product.

Multilouvre, vertical-tray and cascade, continuous-carrier, and drum-type dryers all operate with convective heat transfer coupled with some means of mechanically moving the coal through the dryer. These dryers heat the coal through direct contact with hot gases, which are ordinarily generated in a coal-fired furnace. Moisture is carried out of the dryer in the vapor phase with the exit gas stream, and the coal is carried through the dryer by some type of mechanical conveyor.

The mechanical transport system incorporated in the Multilouvre dryer consists of a series of specially designed flights attached to and carried by two strands of roller chain. The coal is carried up in the flights and then flows downward over the ascending flights. This gentle flowing action exposes all particles to incoming air and results in minimum degradation of the product.

Cascade dryers use a series of shelves arranged like stair steps. Wet coal is fed to the top shelf by a rotary feeder. The coal is transported through the dryer by vibrating the shelves, which causes the coal to cascade down through the shelves to the bottom of the dryer. There, it is collected and removed by a conveyor. Residence time of the coal in the dryer is controlled by adjusting the pitch of the shelves.

Continuous-carrier dryers feed coal to the top of inclined reciprocating screens. There are two screen decks, and the top deck feeds the lower deck. The reciprocating motion of the screens combined with gravity cause the coal to flow through the dryer. The drying-gas flow is alternated between the two decks about once each second. The 
alternating-gas flow results in two phases of moisture removal: one by evaporation and one by mechanically squeezing the water from the coal.

The drum-type or Rotolouvre dryers consist of a solid cylindrical outer shell with a concentric inner shell composed of full-length overlapping louvres. The inner shell is slightly conical with the large end at the dryer discharge. The inner drum revolves slowly, which causes the coal to gently travel toward the discharge end. The drying medium, typically heated air, is introduced through the louvers, permeates the bed, and thoroughly contacts each particle.

Multilouvre, cascade, continuous-carrier, and drum-type dryers all offer the advantage of relatively gentle mechanical transport of the coal. Although these systems limit the extent of particle-size degradation through the use of mechanical transport systems, the mechanical systems impose some limitations. Restricted dryer capacity and high maintenance requirements have resulted in a steady decline in the use of these dryers in favor of the fluidized-bed-type dryers (Elliot 1981).

Developmental Drying Technologies. A variety of technologies are represented in drying processes currently under development (Davy McKee 1984). Hot-water dewatering and decarboxylation employ similar principles. These technologies use hot-water slurry-steam thermal dewatering, require a high-pressure treating reactor, alter the structure of micropores to prevent reabsorption, and require additional drying of the coal after dewatering.

The vapor recompression processes reduce process energy requirements by compressing water vapor to a higher pressure and using the steam to return heat to the drying operation. vapor recompression allows much of the heat used to vaporize the water in the coal to be returned to the drying process at an elevated temperature. Vapor recompression has been tested in pilot plants but is not known to have been used for drying coal on a commercial scale. The process should offer high thermal efficiency but will require high capital and maintenance costs.

The multistage, fluidized-bed drying process achieves above average thermal efficiency by recompressing water vapor from the first stage and using the resulting steam to heat and fluidize the second stage. A portion of the water vapor from the first stage is recycled to fluidize the first stage, which is heated by condensing steam within tubes in the coal bed. The process is complex, requiring compressors, blowers, and a condenser; all of which add to capital and maintenance costs.

A solar drying process has been proposed in which a slurry of coal is pumped to drying ponds where water evaporates. The coal is then stockpiled, and further air drying takes place. solar drying is dependent upon climatic conditions that are not common to the major western coal-producing regions. Slurrying coal for transport to a dryer is impractical, and this process is probably only applicable to dewatering coal that has been slurried for another reason. 
steam drying processes dry coal by heating it with steam under pressure. Some of the water is driven off the coal in the liquid state; thus, the process energy requirements are reduced. At temperatures somewhat above those normally used in evaporative drying, the coal structure is altered, and carbon dioxide and water are driven from the coal. The treatment causes shrinkage, removes water, and stabilizes the lump, which results in improved handling and weathering properties of the dried coal. The coal is also made hydrophobic by the treatment.

The Fleissner process is a form of steam drying that has operated commercially in Europe as a multivessel batch process since 1927. The principle of altering the coal structure remains attractive, and the process has been investigated through pilot-plant work at the Grand Forks Energy Technology Center and the University of North Dakota. The materials handing difficulties associated with high-pressure batch reactors has made the Fleissner process economically unattractive for drying coal in the United States (Gronhovd et al. 1982).

The Koppelman process is a proprietary, continuous, steam-drying process in which the coal is pumped into a high-pressure (1500 psig) tubular reactor in the form of a coal-water slurry. The process heats coal to temperatures above those used in evaporative drying and partially pyrolyzes the coal. The partial pyrolysis releases oil from the coal; this makes extensive water cleanup necessary. Bone-dry coal can be produced by the Koppelman process, but the product is cooled with water, which results in about 58 surface moisture. The final product does have an enhanced heating value that improves the economics of transporting the coal over long distances. However, high-pressure operation and the use of extruders are definite disadvantages of the process.

Developmental work on several drying process that do not use convective heat transfer has been conducted. These processes use conduction and/or radiation as the method of heat transfer. Among these dryers are various heated conveyor systems, such as screw conveyors, that are heated by recirculating a heat transfer medium, typically a thermal oil, through the hollow screw and around the conveyor trough. The heat conducted to the coal by the conveyor surface evaporates moisture, which is carried away by a minimal gas flow. The major advantage of these dryers is the low gas flow. This results in minimal dust entrainment and less difficulty in meeting particulate emissions standards.

The major disadvantage of conductive dryers results from the large heat-transfer surface area needed to ensure that each particle is heated evenly. Heat transfer is not nearly as effective as in the fluidizedbed units. For western coal, from which large quantities of moisture must be vaporized, the units will have to be very large. Although mechanical transport of coal through the dryer may be desirable from an emissions standpoint, it necessarily involves moving parts in a lessthan-ideal environment, which adds to maintenance costs.

Coal drying through direct contact with hot oil has been j.nvestigated. In this process, the coal is immersed in a bath of heated oil for a time sufficient to bring the coal to the desired moisture 
content (Severson 1972). The major problem associated with hot oil drying is separation of the coal from the drying oil. Hot oil drying may find application in conversion processes where the reactor is fed with a coal-oil slurry; however, for drying utility steam coal, an extremely inexpensive oil will be necessary.

steam filtration is a thermal process in which dewatering of filtercake is enhanced by the addition of heat supplied by steam. The final step in the mechanical dewatering of fine coals after wet beneficiation processes is typically a vacuum filtration process. The addition of heat to the filter cake lowers interstitial surface tension and increases fluidity of the water in the cake allowing for easier removal at the vacuum filter. Steam filtration basically involves covering the filter with a suitable hood through which steam can be introduced to the cake. Very rapid heat transfer in the capillary bed results in the formation of a condensation front composed of condensed steam and residual liquid. This condensation front effectively seals the pores of the filter cake, and prevents raw steam from passing directly into the filter drainage (Dahlstrom and silverblatt 1973).

Steam filtration has proven to be an effective method for reducing the moisture content of the filter cake that results from cleaning of coal fines. This process is used for removing surface moisture added in fine-coal-washing circuits; however, because virtually no western coal is washed, steam filtration has found no application in the West. To be practical, western coal-drying technologies must be capable of reducing inherent moisture as well as surface moisture. Therefore, steam filtration will probably be of little significance in the preparation of western coals.

An inclined fluidized-bed (IFB) drying process is under development at the Western Research Institute in Laramie, Wyoming. The key element of the inclined fluidized bed is a gas distributor plate shaped as an elongated rectangle and inclined from the horizontal on its long axis. This distributor plate separates a gas-inlet plenum below and a particle disengaging space above. Fluidizing-gas inlets and outlets are arranged to provide gas flow perpendicular to the distributor plate. Feed enters the bed at the elevated end of the distributor and flows down the incline to the lower exit. Solids transport is essentially plug flow, and the fluidizing gas moves perpendicular to the direction of solids transport.

The bench-scale tests were conducted in a dryer that consists of two identical inclined fluidized beds. The first bed acts as a dryer, and the second bed acts as a cooler. The beds used in the tests were 60 inches long with distributor areas of about $0.4 \mathrm{ft}^{2}$. The beds were separated by a pair of lock-hopper valves to isolate the beds pneumatically. A feed rate of ten $\mathrm{lb} / \mathrm{hr}$ of moist coal was supplied to the upper bed by a screw feeder, and carbon dioxide gas was used to fluidize both beds.

The IFB dryer system was designed specifically for western coal drying (i.e., to efficiently remove inherent moisture during the falling-rate portion of the drying curve). This is accomplished by providing a high moisture-concentration gradient and successively hightr 
temperatures as the coal passes through the dryer. The fluidized state allows for high heat and mass transfer coefficients. The plug flow characteristic of the bed allows successively higher temperatures and continuous exposure of the coal to hot, dry gas to carry the moisture out of the dryer.

Design of the IFB gystem also addresses many of the safety and operational problems associated with thermal coal dryers. By operating with recycled carbon dioxide gas, the potential for fires and explosions is eliminated. The beds operate with minimal fluidization, which decreases the problems of dust entrainment and particle-size degradation. Ambient humidity conditions do not affoct the dryer operation, and the dryer has no moving parts.

Bench-scale testing of the IFB dryer at the Western Research Institute demonstrated that coal fines (minus 28 mesh) can be dried to less than 1 wt 8 moisture with less than 15 wt 8 elutriation. The dried product absorbs significantly less moisture than the feed coal or coal dried with conventional processes using air and lower drying temperatures. Fugitive dust emissions from the dried coal are much lower than from the feed coal, and the danger of fires and explosions has been minimized. The dried coal is more susceptible to spontaneous ignition than the feed coal; however, it has not been determined if this increase is likely to cause problems in storage and handling of the product (Boysen 1990).

Hitachi Ltd. is developing a drying process specifically to upgrade low-rank coals. The process is based upon a combination of drying and low-temperature carbonization. Raw coal is fed to a dryer and then to a carbonizer unit; there, it is heated to $349-399^{\circ} \mathrm{C}\left(660-750^{\circ} \mathrm{F}\right)$. The coal is then cooled and coated with the tar that is generated in the carbonization process.

A pilot plant was constructed to test the process after successful laboratory-scale batch testing. The pilot-plant production is 2.6 tons per day with a raw coal feed of 3.9 tons per day. An upgraded product was produced using feed moisture and heating values of 24.7-30.38 and $7,690-8,960 \mathrm{Btu} / \mathrm{lb}$, respectively. The moisture was reduced to $8.8-$ 12.98 , and the heating value of the product was $10,780-11,610 \mathrm{Btu} / \mathrm{lb}$. The oxidation rate at $45^{\circ} \mathrm{C}\left(113^{\circ} \mathrm{F}\right)$ indicates liability toward spontaneous combustion. In these tests, the oxidation rate decreased. This suggests an increase in stability toward spontaneous combustion over the raw coal. The coal particle size is decreased by this upgrading process, and the quantity of fine coal is increased slightly. However, Yamamoto (1986) claims that even though particle size is decreased, dustiness is not increased above that of the raw coal.

The Hitachi drying process seems very promising. It addresses two of the major concerns associated with dried low-rank coals: spontaneous ignition and dustiness. The process is somewhat complicated from a mechanical standpoint. similar product properties may be attainable with processes that mobilize the coal tar and exude it to the particle surface without actually removing the tar and recoating the particle. However, these processes have not been demonstrated at a scale sufficient to allow comparison with the Hitachi process. 
A drying process for low-rank coal patented by Western Energy (1988) claims to remove a substantial portion of the coal moisture and other impurities including sulfur. The coal is subjected to a superheated gaseous medium, thereby, substantially desorbing the moisture from the coal. A portion of the superheated gases is recycled back through the coal being dried. Sufficient heat is added to maintain the recycled gas in a superheated condition. The process claims to produce a dried, substantially purified product that retains a substantial portion of its volatile content, has an improved heat value, and will not reabsorb substantial moisture when transported and stored (Western Energy 1988).

A large number of devices have been developed over the years for reducing the moisture content of low-rank coals similar to those in the western United states. Several basic methods have been devised beginning with the Fleissner process and progressing through the various fluidized-bed driers now being developed. In the last sixty years, many patents have been issued for various methods of drying low-rank coals, but no one process has gained significant acceptance over the others.

Some processes, based upon hot water or high-temperature steam, may be applicable to the preparation of dried coal slurries for pipeline transport. However, the high pressures required and the difficulties encountered in moving solids in and out of high-pressure reactors will probably render these processes too expensive for drying coal transported by rail. The demonstration of an environmentally acceptable drying process with minimal process severity, low initial and operating costs, minimized product-size degradation, and maximized product stability will be a major accomplishment for use on western coal.

Briquetting and Pelletizing. Briquetting and pelletizing technologies have long been used to convert low-rank coal into higher quality solid fuels. The friable high-moisture coal can be converted to a hard compact briquette or pellet that has increased heating value and improved storage and handling characteristics. The pellets or briquettes are commonly carbonized to create a smokeless fuel for domestic use.

The process of briquetting consists of applying pressure to a mass of particles to form an agglomerated mass. An additional binder, such as asphalt, may or may not be added. Briquetting is commonly conducted at temperatures sufficiently high $\left[0-66^{\circ} \mathrm{C}\left(100-150^{\circ} \mathrm{F}\right)\right]$ to enhance the plasticity of the coal particles. Typically, extrusion presses operate at pressures of about 10 ton/inch ${ }^{2}$ without additional binder. Double roll presses operate at about 1 ton/inch ${ }^{2}$ and an additional binder is commonly required (Berkowitz 1979).

Briquetting has been practiced commercially for over two hundred years, and the process has been developed to a high level of macurity through the application of experience gained over the years. The production and sale of low-rank coal briquettes in the United states has seen minimal development, but this is largely due to the lack of a domestic market for the product rather than a lack of adequate technology (Gronhovd et al. 1982). 
The use of briquetting to stabilize dried western coal against moisture reabsorption and spontaneous ignition may find increasing application in the future. Briquetting can produce a highly stable and highly uniform solid fuel. Many of the problems currently associated with the storage, handling, and use of low-rank coals can be mitigated by appropriate briquetting technologies. Briquetting can be used to generate a valuable, easily transportable product from coal fines and may prove valuable in the production of high-grade solid fuel for the export market.

Pelletizing processes use conditions that are much less severe than those used in briquetting processes. Raw coal is mixed with a binder and discharged onto a rotating pelletizing disc; the rolling motion forms an agglomerated material. The pellets formed on the disc (greenballs) are then fed to a drier where the moisture content is reduced. Pelletizing produces a stable and uniform fuel product and eliminates the problems of dustiness, spontaneous ignition, and moisture absorption associated with handling and storage of western low-rank coals (Bechtel National 1981).

Considerable moisture must be left in the pellets to retain acceptable strength. The moisture content of the pellet is significantly lower than that of raw lignite, but it does not represent a significant decrease for subbituminous coal. Currently, the processes are more applicable to lignites, for which all product properties are improved, than to subbituminous coals, for which the main improvements are to already-acceptable, although not ideal, handling and storage characteristics.

Pelletizing has not yet gained commercial acceptance in the United states, but it does offer a cost-effective method of eliminating the handling, transportation, and storage problems associated with western low-rank coals. The need of an added binder, with its associated costs, and the rather high moisture content of the pellets are the most important problems associated with pelletizing subbituminous coals. coal-derived humic acid binders (Wen et al. 1986) may help improve the economics of pelletizing processes and make them more desirable as a means of upgrading low-rank coals.

\section{BEST TECHMOLOGIES FOR UPGRNDIMG WESTERA COAL}

As a clean low-sulfur utility fuel, western coal should gain an ever-increasing share of the coal market as environmental awareness and the demand for electricity continue to increase through the 1990s. The use of western coal is currently limited by several factors. Some of these factors are related to the coals characteristics, and others are political or geographic. Coal preparation cannot change the political implications of replacing part of the high-sulfur eastern coal with lowsulfur western coal, nor can it bring the western coal fields closer to eastern markets.

Appropriate preparation techniques can, however, be used to modify the characteristics of western coal that limit its use in the eastern 
United states. Table 5 illustrates the value of thermal drying as a means of upgrading western oubbituminous coal to meet coal specifications of eastern electric utilities. Perhaps the most significant of the characteristics of western subbituminous coals is the low heating value. Second in importance, and largely responsible for the low heating value, is the high moisture content of western coal. Finally, high reactivity and weathering characteristics increase the difficulty of handling and storing western coal.

Table 5. R.O.M, and Thernal-Dried Pouder River Basin Coal with Coal specifications for an Eastorn utility

$\begin{array}{lll}\text { PP\&L Montour } & \text { R.O.M. Powder } & \text { Thermal Dried } \\ \text { station Spacs. } & \text { River Basin Coal } & \text { PRB Coal }\end{array}$

\begin{tabular}{lccc}
\hline & & & 0.6 \\
Sulfur & 2.28 & 0.488 & 6.7 \\
Moisture & 15.08 & 4.78 & $<1.08$ \\
Btu/1b & 6.08 & 29.28 & $-12,230$ \\
\hline
\end{tabular}

Moisture reduction can significantiy increase the heating value of western coal and eliminate many problems associated with its use. Most electric utility companies east of the Mississippi River have boilers designed to burn coal of lower moisture than the coals commonly produced in the West. The use of raw western coal in these boilers has required a significant derating of boiler capacity that can be very costly at times of peak demand. In addition to increasing the heating value of western coals, moisture reduction can (1) lower transportation costs, (2) improve burning qualities of the coal, (3) reduce boiler operating and maintenance costs, and (4) increase boiler capability. Reduction of transportation costs on a per Btu basis and increased boiler capabilities are areas with the greatest potential to offset preparation costs.

Tests conducted by Commonwealth Edison at its Pekin, Illinois, steam-electric power station confirmed the value of thermal drying as a means of upgrading western coals. Dried western subbituminous coal from Decker, Montana, was burned successfully in boilers designed to use Illinois coal. Tests compared the burning characteristics of this dried coal with those of the Illinois coal normally used and the raw Montana coal. The dried Montana coal provided the same maximum steam flow as the Illinois coal, whereas the raw Montana coal provided about 928 of the maximum steam flow obtained with the Illinois coal.

Tests were conducted in a B\&W cyclone 850-MW twin boiler unit. One of the twin boilers used the normal Illinois coal, and the other was fed with the Montana coals. 
This allowed instant comparison of operating data and a good evaluation of the dried coal performance. The only operational problem encountered with the dried subbituminous coal was excessive dusting in the open conveyor runs and transfer points into the coal silos. The existing vacuum dust-suppression system, which is marginal with the Illinois coal, could not handle the amount of dried coal dust (Wegert and Jensen 1976).

In conjunction with the U.S. Bureau of Mines, Grand Forks station, railroad transport and long-term storage of dried western coals was tested. These tests showed that the dried coal could be successfully transported and stored. Coal heating during shipment was controlled; however, air leakage around poorly fitting doors in some bottom-dump cars resulted in hot spots. Compaction of the storage piles was required to prevent heating and fires during storage. Compaction is used with any raw coal storage and, therefore, does not constitute a special constraint for the use of dried western coal.

Dried coal and various blends of run-of-mine and dried coals from Amax Coal Company's Belle Ayr mine have been test-burned at several facilities. Orders for blended and dried coal show that this product is acceptable. The Amax dxied coal product has a heating value of about $10,400 \mathrm{Btu} / \mathrm{lb}, 10$ to 128 moisture, and 0.38 sulfur. Dried coal for a test burn by the Fremont, Nebraska, Department of Utilities reportedly sold for $\$ 14 /$ ton F.O.B. (Glass 1990).

The results of Commonwealth Edison tests, Amax test burns, and other bench- and pilot-scale tests suggest that dried western coal can be used successfully in boilers designed to burn other coals. Thermal drying can increase the heating value, reduce transportation costs, improve boiler capability and capacity factor, improve boiler efficiency and reduce maintenance, and reduce coal-conveying problems associated with wet coal. Thermal drying is clearly the best available technology by which to upgrade western coal for the utility market.

One major problem with the use of dried western coal is excessive dustiness. Currently, oil-spray treatment is the most viable method for dealing with the dust problems associated with dried western coal. The combined cost of the treatmont oil and the equipment needed to store and apply the oil is typically not fully offset by the increase in the product heating value attributable to the oil treatment. An improved method for reducing the dustiness and increasing the stability of dried western coal will increase the desirability of upgrading western coal by thermal drying.

\section{RECOMMENDED AREAS FOR FURTHER RESEARCH}

Extensive research has been conducted into advanced coal preparation technologies, most of which have a goal of decreasing precombustion sulfur levels. Western coal benefits little from these efforts. Western coal is already low in sulfur, and almost no western subbituminous coal is given more extensive preparation than crushing to size. There are, however, several areas in which additional coal preparation research can be of great benefit to western coal use. Mineral-matter and sulfur 
reduction are the key elements of eastern coal preparation, whereas moisture reduction and product stability are the keys to western coal preparation.

Thermal drying clearly offers the greatest potential for upgrading western coal; however, conventional coal-drying technologies all exhibit some problems when applied to this resource. Most of the dryers operating in the United States were designed to remove surface moisture from bituminous coal. Surface moisture can be effectively removed without heating the coal particles above $100^{\circ} \mathrm{C}\left(212^{\circ} \mathrm{F}\right.$, McMorris 1963). However, western coal dried under these conditions will quickly reabsorb moisture to near its predried level upon exposure to high humidity (Willson et al. 1987).

The key goal of research activities in western coal preparation should be the development and demonstration of an economical moisturereduction process that is capable of generating a dried coal with a minimal tendency toward moisture reabsorption. The process should be a continuous one that can dry large coal particles (up to 1.5 or 2 inch), while retaining particle strength and integrity. The dried coal should be stable against spontaneous ignition and excessive dustiness when handled and stored by conventional methods. The process should be mechanically simple and maximize the use of proven standard industrial components. Finally, the process should be safe and environmentally sound (i.e., generating environmentally inert byproducts with minimized disposal problems).

Currently available and developing coal drying technologies should be carefully examined for their potential to meet these rriteria. Those technologies that exhibit the greatest potential should be advanced to the demonstration stage and carefully evaluated in terms of process economics and the above-listed criteria. The development of an appropriate drying technology for western coal will be of major significance in increasing the marketability of this resource.

Research activities in the area of product stability correlate closely with coal drying. Drying tends to increase the magnitude of some of the handling and storage problems that are commonly associated with western low-rank coals such as spontaneous combustion and excessive dustiness. Solutions that are sufficient for the handing of raw western coal may not be acceptable if the coal has been dried.

Fundamental research in the area of spontaneous combustion has not produced a complete understanding of the mechanisms responsible for this phenomenon, but many contributing factors have been identified. A more utilitarian approach to the problem of spontaneous combustion may be of significant immediate value to the western coal industry. Research directed toward developing a standardized testing method, which can be used to predict the pyrophoricity of a given coal under specific ambient conditions, will greatly benefit the western coal producers.

An improved method of determining equilibrium moisture will benefit the western coal industry, particularly as the use of coal drying increases. Current methods of determining equilibrium moisture are useful for comparing the tendency of various coals toward moisture 
absorption. However, these methods are of little value for predicting the moisture content of a given coal under various real conditions of storage and use. Development of a standard method that can be used to predict equilibrium moisture under various ambient conditions typical of different parts of the country will be a valuable tool to be used in optimizing drying operations.

Research aimed at the development of methods for transporting and storing ultrafine coal will benefit the entire coal industry. Modern mining and preparation methods are continually increasing the amount of ultrafine coal that is produced, and methods to efficiently use this product are needed.

Briquetting and pelletization are used extensively in other countries; a good deal of the production is devoted to the domestic solid-fuels market. Because a significant domestic market is lacking, interest in briquetting is minimal in the United states. Research is warranted on the use of briquetting as a means of providing a highly stable solid fuel that has uniform and predictable burning, crushing, and handling characteristics.

Tightening environmental regulations and the need to optimize boiler efficiency make it increasingly difficult for coal users to tolerate variations in fuel quality. In the near future, briquetting or pelletizing may find increasing application as the final step in many coal preparation processes that generate a premium fuel from raw coal.

The economic figures available for the various upgrading technologies suggested for western coal are difficult to interpret. Different methods of assessing capital costs, multiple use of various ancillary equipment, and the proprietary nature of some economic data make a consistent cost comparison of upgrading technologies impossible. A standardized economic evaluation of available and proposed technologies for upgrading western coals will of great value as the use of this resource increases. 
The authors wish to express their sincere appreciation to the U.S. Department of Energy, Morgantown Energy Technology Center for funding this work, under contract number DE-FC21-86MC11076. We also wish to extend our thanks to the western coal producers who provided information used in the preparation of this report.

\section{DI8cturyat}

Mention of specific brand names or models of equipment is for information only, and does not imply endorsement of any particular brand. 
Babcock and wilcox Company, 1972, Steam/Its Generation and Use, New York, NY.

Bauer, L.G., 1980, Thermal Drying of Western Coal--A Review Paper, Proceedings of the Western Regional Conference on Gold, silver, Uranium and Coal, Black Hills Section, AIME, Rapid City, SD, Vol. II.

Bechtel National, 1981, Western subbituminous Coals and Iignites, Research Project 1030-11, Final Report, San Francisco, CA 94105.

Berkowitz, N., 1979, An Introduction to Coal Technology, Academic Press, New York, NY.

Boysen, J.E., C.Y. Cha, F.A. Barbour, T.F. Turner, T.W. Kang, M.H. Berggren, R.F. Hoqgett, and M.C. Jha, 1990, Development of an Advanced Process for Drying Fine Coal in an Inclined Fluidized Bed, U.S. Department of Energy Report No. DOE/PC 88886-T5.

Dahlstrom, D.A., and C. Silverblatt, 1973, Production of Low Moisture Content Fine Coal without Thermal Drying, Mining Congress Journal, December, p. 32-40.

Davy Mckee Corporation, 1984, Comparison of Technologies for Brown Coal Drying, Melbourne, Australia, unpublished report.

Deurbrouck, A.W., 1971, Hashability Examinations of Wyoming Coals, U.S. Bur. of Mines, RI 7525, p. 47 .

Deurbrouck, A.W., 1985, A Coal Preparation Editorial, Journal of Coal Quality, November, p. 6-7.

Elliot, M.A., ed., 1981, Chemigtry of Coal utilization, second Supplementary Volume, John Wiley \& Sons, New York, NY.

EPRI, 1980, Coal Resource Information, Electric Power Research Institute, Palo Alto, CA.

Glass, G.B., 1982, Coal Deposits of wyoming, Geological survey of Wyoming, Laramie, WY, Reprint No. 39.

Glass, G.B., 1983, Description of wyoming Coal Fields and seam Analyses, Geological survey of Wyoming, Laramie, WY, Reprint No. 43.

Glass, G.B., 1990, Wyoming Geo-Notes, Geological survey of Wyoming, Laramie, WY, No. 25 .

Glass, G.B., 1990, Wyoming Geo-Notes, Geological survey of wyoming, Laramie, WY, No. 28 .

Gronhovd, G.H., E.A. Sondreal, J. Kotowski, and G. Wiltsee, 1982, LowRank Coal Technology, Noyes Data Corporation, Park Ridge, NJ.

Hutton, C.A., and R.N. Gould, 1982 , cleaning up Coal, Ballinger Fublishing, Cambriage, MÄ. 
Jackson, D., 1978, wyoming Gets its First Prep plant, Coal Age, November, p. 81-85.

International Energy Agency, 1985, The Clean Use of Coal, Organization for Economic Co-operation and Development, Paris, France.

Keystone Coal Industry Manual, 1987, McGraw-Hill, New York, NY.

Leonard, J.W., and D.R. Mitchell, eds., 1968, Coal Preparation, The American Institute of Mining, Metallurgical, and Petroleum. Engineers, New York, NY.

Lowry, H.H., 1945, Chemistry of Coal Utilization, Vol. 1, John wiley and Sons, New York, NY.

Luckie, P.T., and E.A. Draeger, 1976, The Very Special Considerations Involved in Thermal Drying of Western Region Coals, Coal Age, January, p. 106-109.

McMorris, W.L., 1963, Heat Dryer Ignitions ... Prevention and Control, Coal Age, January, p. 88-90.

Mishra, S.K., and R.R. Klimpel, 1987, Fine Coal Processing, Noyes Publications, Park Ridge, NJ.

Moody, D. C., 1989, Energy for the Next Decade and Beyond, Landmarc, National Coal Association, Washington, DC, 12(2).

Rhodes, E.0., 1949, German Low Temperature Tar Industry, U.S. Department of Interior Report I.C. 7490, U.S. Government Printing office, Washington, DC.

Rice, N., and T.L. Johnston, 1951, Fluidized Drying and Briquetting LowRank Western Coals, University of Wyoming Natural Resources Research Institute, Laramie, WY.

Schobert, H.H., 1987, Coal the Energy Source of the Past and Future, American Chemical society, Washington, DC.

Schreckengost, H.A., 1963, Safety Factors Associated with Thermal Coal Drying, Mining Congress Journal, July, p. 28-32.

Severson, D.E., 1972, Dehydration of Low-Rank Coal in Hot oil, University of North Dakota Engineering Experiment station, Grand Forks, ND.

Tsai, S.C., 1982, Fundamentals of Coal Beneficiation and Utilization, Elsevier Scientific Publishing, oxford, NY.

Wegert, C., and H. Jensen, 1976, Enriching Western Coals by Thermal Drying and Oil Treatment, Coal Age, May, p. 96-100.

Wen, W.W., P.D. Bergman, and A.W. Deurbrouck, Sept 1-5, 1986, A Humic Acid Binder for Pelletizing of Fine Coal, Pittsburgh Energy Technology Center, U.S. Department of Energy, Pittsburgh, PA, 10th International Coal Preparation Congress. 
Western Energy Company, 1988, Butte, MT, U.S. Patent \#4,725,337, February 16,1988 .

Willson, W.G., S.A. Farnum, G.G. Baker, and G.H. Quentin, 1987, Low-Rank Coal slurries for Gasification, Fuel Processing Technology, 15: p. 157-172.

Yamamoto, A., Y. Nakamura, and J. Tomuro, 1985, Technique for Upgrading of Low-rank Coals, Thirteenth Biennial Lignite Symposium: Technology and Utilization of Low-rank Coals Proceedings Vol. 2, Grand Forks, ND, p. 470-482. 
Ayat, M.G., and B.C. Scott, 1988, Degradation Process in Coal slurry Pipelines, Mining Engineering, p. 885-888.

Banks, w.C., 1985, Export Coal in 1985, Journal of Coal Quality, 4 (4): p. $9-10$.

Berggren, M.H., 1987. Coal Drying Dust Control, unpublished AMAX Coal Company report.

Boley, C.C., and N. Rice, 1949, Briquetting of Dried Low-Rank Western Coals, University of Wyoming, Natural Resource Research Institute, Laramie, WY.

Boron, D.J., and R. Kollrack, 1986, Prospects for chemical Coal Cleaning, Mining Engineering, February, p. 120-122.

Burtron, H.D., 1986, What is the Future for synfuels?, Journal of Coal quality, $5(3)$, p. 84-88.

Cheney, V.A., J.K. Ihrig, and H.E. Swanson, 1979, How to select a Dryer, Chemical Engineering Progress, April, p.40-43.

Chironis, N.P., 1986, Surface Mining of Coal... Growth Through Evolution, Coal Age, June, p. 69-79.

Chironis, N.P., 1987, Advanced Techniques Clean Ultrafine Coal at Homer City, Coal Age, December, p. 68-69.

Chironis, N.P., 1989, Keeping winter Coal Flowing smoothly, Coal Age, september, p. 49-52.

Coal Utilization, 1983, United Nations Educational scientific and Cultural Organization, Paris, France.

Coal Operators and Alaska Leaseholders Association, 1986, Facts on Alaska coal.

Coal Age, 1959, Entrainment Dryer at orient 3 cuts 10 M Moisture Economically, August, p. 102-103.

Coal Age, 1959, Low-Cost Thermal Drying, Increased Plant Efficiency, Quality Products, November, p. 118-119.

Coal Age, 1963, Better Dust Collection at Imperial smokeless, May, p. 111-114.

Coal Age, 1965, Thermal Drying of Pelletized 28-Mesh Fines, August, p. 104-105.

Coal Age, 1966 , Vibrating Hopper puts Dryer Back into operation, February, p. 138 .

Coal Age, 1980, Dried Coal is Better Than Wet, May, p. 149-158. 
Coal Age, 1984, Some southern Utilities Find it Cheaper to Import coal, May, p. 19.

Coal Age, 1984, Amax Strives to Extend its Marketing Operation Eastward, May, p. 21.

Coal Age, 1986, Mobil Aims to Enhance Western Coals with New Drying Process, February, p. 80-81.

Coal Age, 1986, Eastern Coal Outlook Depends on clean Coal Funding, January, p. 15 .

Coal Age, 1986, Wyoming Coal Could Lose Markets to Foreign Producers, January, p. 27 .

Coal Age, 1986, FBC Could Ignite Coal Burning Revolution, February, p. 11-13.

Coal Age, 1986, Top Producers Had a Bad 1985, April, p. 11-17.

Coal Age, 1987, Chemists' Discovery Could Aid High sulfur Coal, May, p. 19.

Coal Age, 1987,1987 Census of North American Preparation Plants, January, p. $39-49$.

Curlett, P.I., B.C. Krippene, and J.W. Galambas, 1984, How Utilities Determine Coal Prices, Coal Age, February, p. 74-77.

Durant, J.F., R.W. Borio, B.W.' Griffith, and A.A. Levasseur, 1989, The Effect of Coal cleaning on Boiler Performance, presented at the Fifteenth Biennial Low-Rank Fuels Symposium, st. Paul, MN.

Galuska, P., 1986, 1911-1986 Coal's Rise and Fall and Rise, Coal Age, June, p. 47-55.

Glass, G.B., 1984, Analysis and Measured sections of 25 Coal samples from the Hanna coal Field of southcentral Wyoming, Geological survey of Wyoming, Laramie, WY, Reprint of Investigation No. 27 .

Glass, G.B., 1976, Review of Wyoming Coal Fields, Geological survey of Wyoming, Laramie, WY, Bulletin No. 58.

Glass, G.B., 1975, Using Published Wyoming Coal Analyses, Geological survey of Wyoming, Laramie, WY, Reprint No. 31 .

Glass, G.B., 1975, Analysis and Measured sections of 54 wyoming Coal Samples, Geological survey of wyoming, Laramie, wy, Report on Investigations No. 11 .

Glass, G.B., 1976, Wyoming Coal Directory, Geological survey of Wyoming, Laramie, WY, Public Information Circular No. 3. 
Glass, G.B., 1973, Profiles of Wyoming Coal Mines, Geological survey of Wyoming, Laramie, WY, Reprint No. 27 .

Glass, G.B., and R.W. Jones, 1974, Bibliography of Wyoming Coal, Geological survey of Wyoming, Laramie, WY.

Green, P., 1984, Upgrading Preparation Plants, Coal Age, January, p. 4649.

Green, P., 1987, Developing Prep Processes Strive for Perfect Coal, Coal Age, January, p. 35-37.

Hand, J.W., 1976, Drying of Western Coal, Mining Congress Journal, May, p. 30-32

Hoskin, J.A., 1928, A study of spontaneous Combustion in storage Coal, Purdue University, Lafayette, IN.

Holley, C.A., and J.M. Antonetti, 1977, Agglomeration of Coal Fines, IBA Proceedings Volume 15, The Institute for Briquetting and Agglomeration, Montreal, Canada.

Jackson, D., 1984, Fine Coal Spirals, Coal Age, June, p. 66-69.

Jarboe, T.B., and H. Wen, 1988, Circulating Fluidized Bed Power Plants offer Improved Technology for Burning Low-Grade Coals, Mining Engineering, November, p. 1021-1023.

Jeglic, M.F., 1986 , Laboratory Device for Evaluating Dust Control Agents, Journal of Coal Quality, 5(3): p. 104-107.

International Energy Agency, 1987, Clean Coal Technology, Organization for Economic Co-operation and Development, Paris, France.

Kaiparowits Coal Development and Transportation study, 1980, Environmental Research \& Technology, Ft. Collins, Co.

Klein, D., 1980, Coal Resource Information Volume 3, Electric Power Research Institute, Palo Alto, CA.

Kumar, D., 1985, System Design for Coal Preparation Plants, Journal of Coal quality, 4(2): p. 80-83.

Lemke, K., 1965, Using steam on Vacuum and Pressure Filters, Mining Congress Journal, March, p. 41-46.

Leonard, J.W., and E.J. Sandy, 1962, Better Coal-Dryer Control, Coal Age, March, p. 94-100.

Lynn, J.R., 1946, Certain Chemical and Physical Properties of several Wyoming subbituminous Coals, University of Wyoming Natural Resources Research Institute, Laramie, WY.

Merritt, R.D., 1987, Alaska's Low-sulfur Coal Resources May Be World's Largest, Journal of Coal Quality, 6(3): p. 104-108. 
Merritt, R.D., 1986, Proposal for Entry of Alaska Coal Data into the National Coal Resources Data system of U.S. Geological Survey, State of Alaska Department of Natural Resources DGGS, Fairbanks, AK.

Mining Engineering, 1988, Amax Builds Large Coal Drying Plant at its Belle Ayr Mine, November, p. 1031-1032.

Mujumdar, A.S., ed., 1987, Handbook of Industrial Drying, Marcel Dekker, New York, NY.

Nowacki, P., ed., 1980, Lignite Technology, Noyes Data Corporation, Park Ridge, NJ.

Paulson, I.E., S.A. Cooley, C. Wegert, and R.C. Ellman, 1976 , Experiences in Transportation of Dried Low-Rank Western Coals, Transactions of Society of Mining Engineers, 260: p. 300-305.

Paulson, L.E., S.A. Cooley, and R.C. Ellman, 1974, Shipment, storage, and Handling Characteristics of Dried Low-Rank Coals, symposium on Technology and Use of Lignite, Grand Forks, ND, BuMines IC 8650, p. 49-75.

Pitt, G.J., and G.R. Millward, 1979, Coal and Modern Coal Processing: An Introduction, Academic Press, San Francisco, CA.

Pings, D., and S.C. Loshbaugh, 1986, Quality Control at Colowyo Coal, Journal of Coal Quality, 5(3): p. 92-94.

Research Needs Assessment by Alaska State Agencies, 1986, state of Alaska, office of the Governor.

Riley, J.T., and J.W. Reasoner, 1985, Continuing the study of SelfHeating in Coal, Journal of Coal Quality, 4(2): p. 47.

Riley, J.T., J.W. Reasoner, S.M. Fatemi, G.S. Yates, K.L. Diedrich, and T.B. Taylor, 1987, Use of Carbon Dioxide to Reduce Self Heating in Barged coal, Journal of Coal Quality, 6(2): p. 64-67.

Rubin, E.S., and I.M. Torrens, eds., 1983, Costs of Coal Pollution Abatement, organization for Economic Co-operation and Development, Paris, France.

Schobert, H.H., 1984, The Chemistry of Low-Rank Coals, American Chemical Society, Washington, DC.

Schreckengost, H.A., and M.S. Childers, 1965, Fire and Explosion Hazards in Fluidized-bed Thermal Coal Dryers, U.S. Bureau of Mines Information Circular 8258 .

Severson, D.E., 1972, Dehydration of Low-Rank Coal in Hot oil, University of North Dakota Engineering Experiment station, Grand Forks, ND. 
Singh, R.N., 1986, A practical system of Claseifying Coal seams Liable to spontaneous Combustion, Journal of Coal quality, 5(3): p. 108112 .

Soderberg, H.E., 1974, Envirommental, Energy and Economic Considerations in Particulate Control, Mining Congress Journal, December, p. $24-29$.

Speight, J.G., 1983, The Chemistry and Technology of Coal, Marcel Dekker, New York, NY.

Turner, J.H., and W.J. Donohue, 1979, Heat Drying of Coal at MidContinent, Mining Conqress Journal, March, p. 17-19.

Western Fossil Fuels R\&D Public Meeting, summary Proceedings, July 26, 1989, U.S. Department of Energy Office of Fossil Energy, Denver, Co.

Wilson, E.B., and F.G. Miller, 1974, Coal Dewatering--Some Technical and Economic Considerations, Mining Congress Journal, September, p. 116121.

Young W.H., and R.I. Anderson, 1959, Thermal Drying of Coal, Coal Age, June, p. 114-115.

Zimmerman, R.E., 1961, Recent Progress in Thermal Drying Ultra-Fine Coal, Mining Congress Journal, September, p. 47-51. 

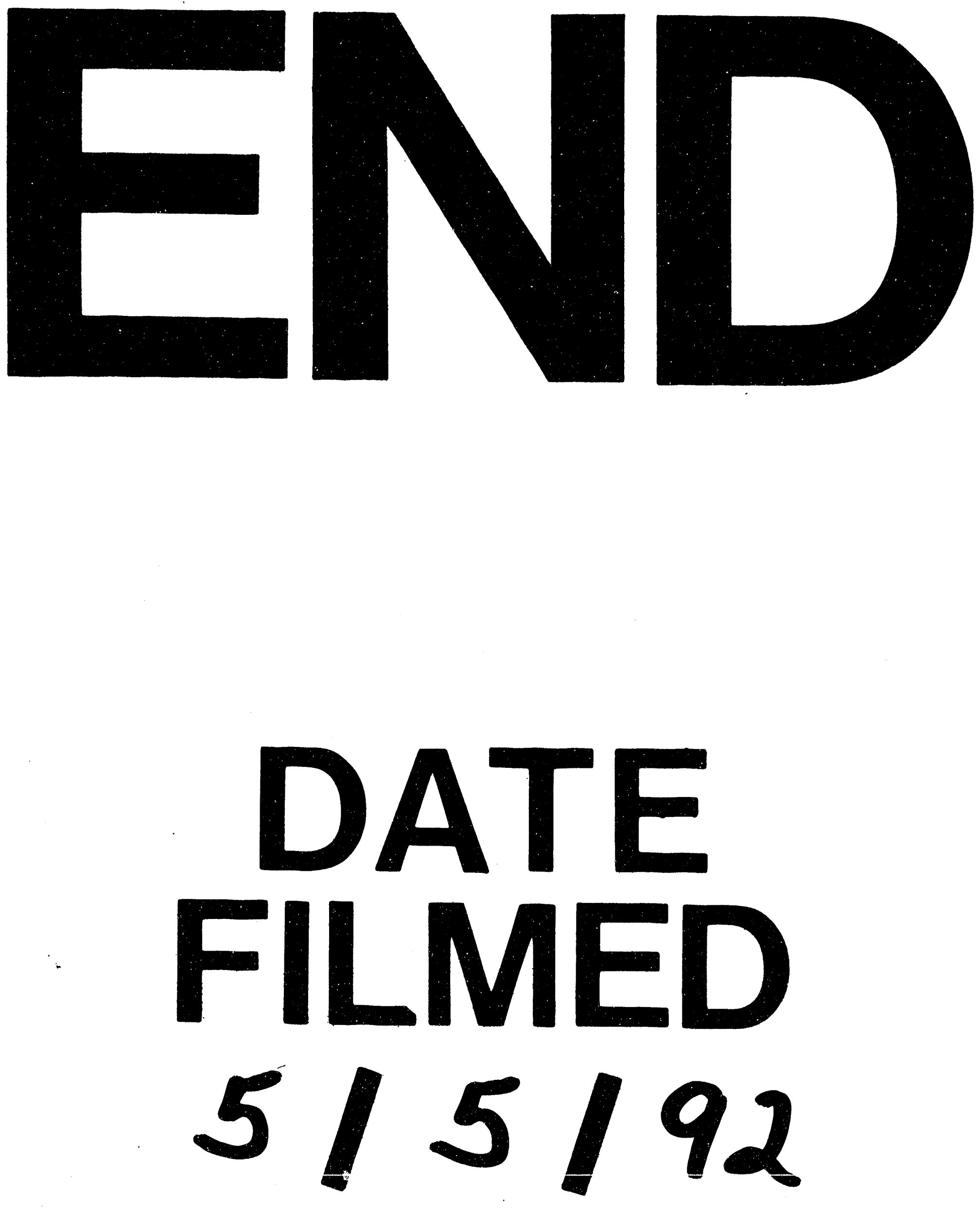

$p$ 
